This item was submitted to Loughborough's Research Repository by the author.

Items in Figshare are protected by copyright, with all rights reserved, unless otherwise indicated.

\title{
Rapid dynamics of cell-shape recovery in response to local deformations
}

PLEASE CITE THE PUBLISHED VERSION

https://doi.org/10.1039/C6SM02560A

PUBLISHER

(c) Royal Society of Chemistry

VERSION

VoR (Version of Record)

\section{PUBLISHER STATEMENT}

This work is made available according to the conditions of the Creative Commons Attribution-NonCommercialNoDerivatives 4.0 International (CC BY-NC-ND 4.0) licence. Full details of this licence are available at: https://creativecommons.org/licenses/by-nc-nd/4.0/

\section{LICENCE}

CC BY-NC-ND 4.0

\section{REPOSITORY RECORD}

Haase, Kristina, Tyler N. Shendruk, and Andrew E. Pelling. 2019. "Rapid Dynamics of Cell-shape Recovery in Response to Local Deformations". figshare. https://hdl.handle.net/2134/36375. 


\section{Soft Matter}

\section{Rapid dynamics of cell-shape recovery in response to local deformations}

\begin{tabular}{|r|l|}
\hline Journal: & Soft Matter \\
\hline Manuscript ID & SM-ART-06-2016-001292 \\
\hline Article Type: & Paper \\
\hline Date Submitted by the Author: & 05-Jun-2016 \\
\hline Complete List of Authors: & $\begin{array}{l}\text { Haase, Kristina; University of Ottawa, Physics } \\
\text { Shendruk, Tyler; University of Oxford, Physics } \\
\text { Pelling, Andrew; University of Ottawa }\end{array}$ \\
\hline
\end{tabular}

\section{SCHOLARONE ${ }^{m}$ \\ Manuscripts}




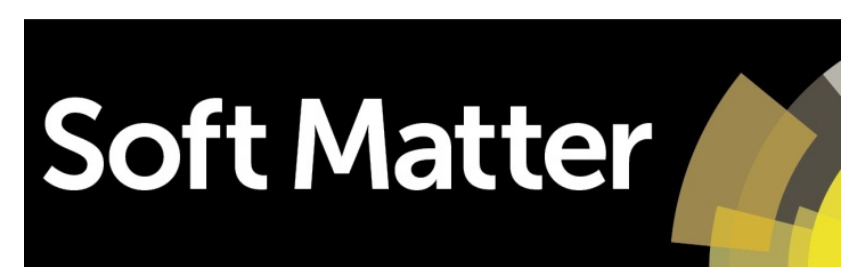

\section{FULL PAPER SUBMISSION}

Where physics meets chemistry meets biology for fundamental soft matter research

2014 Impact factor: 4.029

www.rsc.org/softmatter

Soft Matter has a global circulation and interdisciplinary audience with a particular focus on the interface between physics, biology, chemical engineering, materials science and chemistry.

The following paper has been submitted to Soft Matter for consideration as a full paper.

Soft Matter aims to publish high quality papers reporting on the generic science underpinning the properties, applications, and phenomena of soft matter. The primary criterion for acceptance of a contribution for publication is that it must report high-quality new science and make a significant contribution to its field. Soft Matter is an interdisciplinary journal and suitable papers should cross disciplines or be highly significant within the field from which they originate.

Routine or incremental work, however competently researched and reported, should not be recommended for publication if it does not meet our expectations with regard to novelty and impact.

Thank you for your effort in reviewing this submission. It is only through the continued service of referees that we can maintain both the high quality of the publication and the rapid response times to authors.

We would greatly appreciate if you could review this paper in two weeks. Please let us know if that will not be possible. Please support all comments with scientific justifications or we may be unable to use your report/ask for extra feedback.

Once again, we appreciate your time in serving as a reviewer. To acknowledge this, the RSC offers a $\mathbf{2 5 \%}$ discount on its books: http://www.rsc.org/Shop/books/discounts.asp. Please also consider submitting your next manuscript to Soft Matter.

Best wishes,

Liz Dunn, Executive Editor, Soft Matter 
To the Referees of Soft Matter,

We are pleased to submit our manuscript "Rapid dynamics of cell shape recovery in response to local deformations" by Haase et al. for your consideration for publication in Soft Matter.

Articles examining cell viscoelasticity ${ }^{1}$, AFM, and cell spreading behavior ${ }^{2}$, and theoretical investigations of epithelial properties ${ }^{3}$, published in Soft Matter are cited often. Our article examines the dynamics of soft biological matter, in particular the recovery dynamics of epithelial cells. Our manuscript will appeal to the broad readership of Soft Matter as we look at a fundamental biological problem: cell-shape dynamics of the tethered membrane and cortex, a particularly complex soft biological system. Specifically, we characterize cellshape recovery following unloading from an AFM tip, and use over-damped viscoelasticity to model the response. We apply a mix of experimental and theoretical modeling approaches, including measuring fluorescence intensities of the labeled membrane and cortex, which provides a visual means for confirming cell-shape recovery and validating our model. We also reveal viscoelastic contributions of the cell-shape recovery process through disruption of the cytoskeleton and intracellular pressure.

Examples of cell-shape recovery in the literature often involve chondrocytes and erythrocytes, not epithelia ${ }^{4-6}$. Here, we reveal recovery behavior in HeLa, a cancerous cell line, and other non-cancerous epithelial cells. Using HeLa as a model, we demonstrate simultaneous deformation and recovery of the tethered membrane and cortex. Importantly, we show that cell-shape recovery time is not impacted by load magnitude, nor the duration of loading. Moreover, HeLa rapidly recover their pre-deformed shape following unloading ( $90 \%$ in less than 1s). Highly elastic contributions, demonstrated by our model, account for this rapid response. Cortical actin is a primary regulator, with contributions from intracellular pressure revealed under complete cytoskeleton destabilization. We propose that cell-shape recovery may be a potential indicator of disease, as are other mechanical properties ${ }^{7}$. This stems from our observations of varied recovery times amongst other non-cancerous epithelial cells.

Cell-shape regulation and cell mechanics are highly relevant to the field of soft matter biology. Our work importantly reveals cell-shape recovery as a rapid, viscoelastic response in epithelial cells. We feel that our work will have an appeal amongst the diverse community of readers of Soft Matter.

Thank you, the Referees, for taking the time in reviewing this manuscript.

Sincerely,

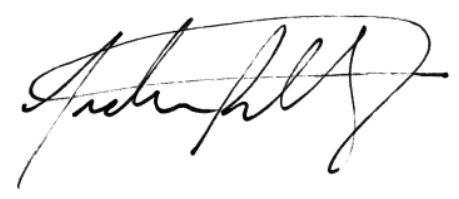

Andrew E. Pelling
Pelling Lab for Biophysical Manipulation University of Ottawa

Center for Interdisciplinary Nanophysics MacDonald Hall

150 Louis Pasteur Ottawa, ON K1N6N5 Canada

Tel: +1 (613) 562-5800, (6965) Email: a@pellinglab.net Web: http://www.pellinglab.net Twitter: @pellinglab 


\section{TED Fellow}

Canada Research Chair in Experimental Cell Mechanics

Associate Professor

Department of Physics

Department of Biology

Institute for Science, Society and Policy

University of Ottawa

Honorary Research Fellow

SymbioticA - The Centre of Excellence in Biological Arts

School of Anatomy, Physiology and Human Biology

University of Western Australia

\section{References}

1. Pietuch, A., Bruckner, B. R., Fine, T., Mey, I. \& Janshoff, A. Elastic properties of cells in the context of confluent cell monolayers: Impact of tension and surface area regulation. Soft Matter 9, 11490-11502, (2013).

2. Vichare, S., Inamdar, M. M. \& Sen, S. Influence of cell spreading and contractility on stiffness measurements using afm. Soft Matter 8, 10464-10471, (2012).

3. Krajnc, M., Storgel, N., Brezavscek, A. H. \& Ziherl, P. A tension-based model of flat and corrugated simple epithelia. Soft Matter 9, 8368-8377, (2013).

4. Ofek, G., Wiltz, D. C. \& Athanasiou, K. A. Contribution of the cytoskeleton to the compressive properties and recovery behavior of single cells. Biophys J 97, 1873-1882, (2009).

5. Shelby, J. P., White, J., Ganesan, K., Rathod, P. K. \& Chiu, D. T. A microfluidic model for single-cell capillary obstruction by plasmodium falciparum-infected erythrocytes. Proceedings of the National Academy of Sciences 100, 14618-14622, (2003).

6. Shieh, A. C., Koay, E. J. \& Athanasiou, K. A. Strain-dependent recovery behavior of single chondrocytes. Biomech Model Mechan 5, 172-179, (2006).

7. Jonas, O., Mierke, C. T. \& Kas, J. A. Invasive cancer cell lines exhibit biomechanical properties that are distinct from their noninvasive counterparts. Soft Matter 7, 11488-11495, (2011). 


\section{Rapid dynamics of cell-shape recovery in response to local deformations}

Kristina Haase ${ }^{1}$, Tyler N. Shendruk ${ }^{2}$, and Andrew E. Pelling ${ }^{1,3,4}$

${ }^{1}$ Department of Physics, MacDonald Hall, 150 Louis Pasteur, University of Ottawa

${ }^{2}$ The Rudolf Peierls Centre for Theoretical Physics, Department of Physics, University of Oxford, 1 Keble Road, Oxford, OX1 3NP, UK

${ }^{3}$ Department of Biology, Gendron Hall, 30 Marie Curie, University of Ottawa

${ }^{4}$ Institute for Science, Society and Policy, Simard Hall, 60 University, University of Ottawa, Ottawa, ON, K1N 6N5, Canada

Author for correspondence:

Andrew E. Pelling

Phone: +1 (613) 662 - 5800 Ext 6965

Fax: +1 (613) $562-5190$

Email: a@pellinglab.net

Key Words: Cell shape, recovery, osmotic shock, atomic force microscopy, cell deformation, viscoelastic response

Running Title: Rapid cell shape recovery dynamics. 


\begin{abstract}
It is vital that cells respond rapidly to mechanical cues within their microenvironment through changes in cell shape and volume, which rely upon the mechanical properties of cells' highly interconnected cytoskeletal networks and intracellular fluid redistributions. While previous research has largely investigated deformation mechanics, we now focus on the immediate cell-shape recovery response following mechanical perturbation by inducing large, local, and reproducible cellular deformations using AFM. By continuous imaging within the plane of deformation, we characterize the membrane and cortical response of HeLa cells to unloading, and model the recovery via overdamped viscoelastic dynamics. Importantly, the majority (90\%) of HeLa cells recover their cell shape in $<1$ s. Despite actin remodelling on this time scale, we show that cell recovery time is not affected by load duration nor magnitude. To further explore this rapid recovery response, we expose cells to cytoskeletal destabilizers and osmotic shock conditions, which exposes the interplay between actin and osmotic pressure. We show that the rapid dynamics of recovery depend crucially on intracellular pressure, and provide strong evidence that cortical actin is the key regulator in the cell-shape recovery processes, in both cancerous and non-cancerous epithelial cells.
\end{abstract}

\title{
Introduction
}

The morphological state of a cell is in a continual state of flux, as a consequence of normal cellular functions and physiological processes. These cellular shape changes are at times drastic, and typically result from actomyosin generated forces, or those arising from the extracellular microenvironment ${ }^{1,2}$. Cells respond to these forces by adapting in a time-dependent manner ${ }^{3}$, the response of which depends on the rate and duration of applied force ${ }^{2,4}$, as well as the mechanical properties of the cell. Both elastic ${ }^{5}$ and viscous ${ }^{6-8}$ cellular behaviours have been observed using direct deformation techniques, such as atomic force microscopy (AFM) ${ }^{9-13}$. Cantilever deflections during constant-height or constant-force experiments result in measureable stress-relaxation and creep compliance curves, respectively ${ }^{14-17}$. Simple mechanical models, including Kelvin-Voigt and the standard linear model ${ }^{17}$, as well as more complex models including power-law and soft-glassy rheology ${ }^{18,19}$ are often employed to extract these mechanical properties. Often broad assumptions, such as cellular incompressibility ${ }^{20}$, are considered in order for these models to fit the data. Given their complex behaviour, it is unclear if an all-encompassing cell mechanics model can be defined. Nevertheless, a systematic characterization of cellular shape change, alongside investigation into mechanical properties, is vital to assess the mechanisms involved in key regulatory behaviours.

Recently, we showed that an intact actin network is critical for resisting large local deformations, demonstrating the importance of cortical prestress in cellular shape change ${ }^{21}$. The actin cortex of HeLa cells, in conjunction with the membrane, recovered cell-shape within minutes following large-magnitude local loads ${ }^{21}$. The contractile actomyosin cortex is well-known to modulate cellular shape changes, as it undergoes remodelling at a relatively fast turnover rate ${ }^{22}$ ( on the order of seconds). However, experimental evidence has demonstrated that actin resists tension, yet buckles under compression at the molecular level ${ }^{23,24}$. This leads to questions surrounding how cells resist external compression, and, importantly, how do cells recover following loading at the macroscale?

Our previous observations of a slow recovery in the absence of an intact cytoskeleton ${ }^{21}$ suggest involvement of other cellular constituents, such as the recently proposed liquid phase of cytoplasm ${ }^{25}$. Recently, force-relaxation curves demonstrated a redistribution of liquid cytosol as responsible for the initial pressure redistribution during external loading of a cell ${ }^{25}$. The cytoplasm was demonstrated to behave as a biphasic material during the initial stages $(\sim 0.5 \mathrm{~s})$ of compression, wherein the liquid cytosol 
was confined to flow through a solid mesh (made up of cytoskeletal filaments and macromolecules) ${ }^{25}$. Hyperosmotic stress, used to increase the solid volume fraction of cells, has also been shown to result in dramatic increases in shear stiffness ${ }^{18}$ and decreased water content increases the viscosity of cells, leaving mainly the cytoskeleton and macromolecules to resist compression. Together, these studies suggest that, while cytoskeletal prestress is required for resistance to deformation, changes in osmotic pressure largely dominate the mechanical properties of the cell.

This interplay between the cytoskeleton and intracellular pressure is responsible for the response and adaptation of cells to deforming forces. However, the majority of research has focused on characterizing the initial cellular response to force ${ }^{26,27}$, and to a lesser extent the adaptive recovery of cells following drastic shape changes ${ }^{28-30}$. To address this gap in knowledge, we systematically characterize the response of the membrane and cortex immediately and following both short (seconds) and long (minutes) durations of mechanical loading. AFM and laser scanning confocal microscopy (LSCM) are simultaneously used to directly visualize and quantify deformation and characteristic recovery (decay) constants of HeLa cells. Employing cytoskeletal inhibitors and osmotic shock conditions demonstrate large contributions of the actomyosin network and osmotic pressure to cell-shape recovery. Recovery, modelled as overdamped viscoelastic membrane dynamics, yields a dominant recovery constant corresponding to a viscoelastic mechanism dictating the response.

\section{Methods}

Cell culture. Details on cell culture and drug treatments can be found in the Supplementary Information.

Dynamic tip-retraction experiments. Briefly, AFM is used to apply a constant force $(10 \mathrm{nN})$ to cells, while high-speed LSCM is used to capture time-lapse images within a plane of visible cell deformation. Fluorescence intensities are correlated to recovery constants of the membrane and cortex. Full details are provided in Supplementary Information.

Viscoelastic model of cell shape recovery. An overdamped telegraph equation is used to model the recovery behaviour of the membrane/cortex as an idealized series of surface elements viscoelastically coupled to the subcellular environment, as fully described in the Supplementary Information.

\section{Results}

\section{Cell-shape recovery dynamics of the membrane and cortex.}

Herein, we develop a framework for direct visual measurement of deformation and recovery dynamics of the cell membrane and underlying cortex of HeLa cells within a monolayer. Resonant-mode LSCM is used to capture local deformations delivered by an AFM tip (Fig. 1a-b). Loads of 10 or $20 \mathrm{nN}$ are applied above the nucleus of cells for both short (15 s) and long durations ( 1 and $10 \mathrm{~min}$ ). Although the nucleus was previously found to insignificantly contribute to long-term shape recovery of HeLa cells ${ }^{21}$, the central region above the nucleus is chosen for consistency. Experiments are performed on HeLa cells transiently expressing EGFP-PH-PLC $\delta$ and LifeAct Ruby ${ }^{21}$, in order to measure the dynamics of both the plasma membrane and cortex, respectively (Fig. 1b). Our previous results showed no difference in stiffness or deformation between single HeLa cells or those cultured in a monolayer ${ }^{21}$. Therefore, experiments are performed within monolayers to maintain a more natural growth environment. During initial approach or retraction of the tip, continuous imaging $(7.69 \mathrm{fps})$ is performed in a single plane $f \sim 2 \mu \mathrm{m}$ below the apical membrane. Imaging in this plane allows for measurements of fluorescence intensity over time where the deformation is clearly visible (Fig. 1C). A specified region of interest (ROI) is used to measure mean intensity over time. 
First, the cell membrane and underlying actin cortex are shown to deform simultaneously with little resistance to force, in response to rapid indentation $(10 \mu \mathrm{m} / \mathrm{s})$ (Supplementary Methods, Fig. S1a and Vid. S1). Using the same imaging approach, both short and long durations of constant force are applied apically to HeLa cells while examining their ability to recover from large local loads. Normalized intensity (recovery) curves, measured from time-lapse images of untreated cells, are fit to a modified box-Lucas equation

$$
I(t)=A\left(e^{-\kappa_{2} t}-e^{-\kappa_{1} t}\right) .
$$

Mean fluorescence intensity $I$ is described by a double exponential with two decay (recovery rate) constants: $\kappa_{1}\left(\mathrm{~s}^{-1}\right)$, corresponding to the initial recovery as the membrane/cortex approaches the imaging plane, and $\kappa_{2}\left(\mathrm{~s}^{-1}\right)$, corresponding to movement of the membrane/cortex surpassing the imaging plane. The unit-less factor $A$ is related to the recovery constants as $A=\kappa_{1} /\left(\kappa_{1}-\kappa_{2}\right)$. Intensity profiles fit to equation (1) demonstrate that $\kappa_{1}$ is dominant in dictating the shape of the recovery curve, with paired $t-$ tests indicating $\kappa_{1}>\kappa_{2}$, in all cases $(P<0.05)$. The majority $(90 \%)$ of intensity profiles for untreated cells behave similarly to the exemplary curve in Fig. 2a; however, a small number (10\%) behave as in Fig. $2 \mathrm{~b}$. Following $1 \mathrm{~min}$ of a $10 \mathrm{nN}$ load, mean characteristic recovery constants measured from fits to equation (1) for the membrane are $2.35 \pm 1.04 \mathrm{~s}^{-1}$ and $0.07 \pm 0.06 \mathrm{~s}^{-1}$ for $\kappa_{1}$ and $\kappa_{2}$, respectively. Typically, intensity profiles of the cortex matched those of the membrane (Fig. S1b). Thus, mean characteristic decays of the cortex ( $\kappa_{1}$ of $2.41 \pm 1.00 \mathrm{~s}^{-1}$ and $\kappa_{2}$ of $0.07 \pm 0.04 \mathrm{~s}^{-1}$ ) were insignificantly different from those of the membrane $(P>0.1)$. Differences between fits of the recovery profiles for the membrane and cortex are attributed to increased noise in RFP images. This comes from out of plane contributions (see Confocal Resolution, Supplementary Methods). Cell-shape recovery occurs independent of cellular adhesion to the AFM tip, as can be witnessed in force-curves (Fig. S1c).

Despite a significant increase in strain (10 and $20 \mathrm{nN}$ in Table S3), doubling the load does not influence the recovery of either the membrane or cortex, as determined by recovery constants (Table S1). Notably, load duration does not influence recovery, despite the fact that actin remodelling certainly takes place within the time frame of our experiment ${ }^{31}$. Initial characteristic recovery constants $\left(\kappa_{1}\right)$ of the membrane and cortex are $>1 \mathrm{~s}^{-1}$ following $15 \mathrm{~s}, 1 \mathrm{~min}$, and $10 \mathrm{~min}$ long durations of $10 \mathrm{nN}$, indicating fast recovery of $<1 \mathrm{~s}$ (Table S1). Box plots demonstrate the variance in secondary recovery $\left(\kappa_{2}\right)$ for the membrane and cortex (Fig. 2c-d). Mean membrane recovery $\kappa_{1}$ is $2.65 \pm 0.27 \mathrm{~s}^{-1}$ for all durations (a recovery rate of $\sim 0.37 \mathrm{~s}$ ). On average, the membrane recovery rate decreases as the membrane and cortex move past the imaging plane $\left(\kappa_{2}=0.12 \pm 0.09 \mathrm{~s}^{-1}\right)$.

In order to characterize overall differences in cellular recovery, we define a cell as "recovered" when the membrane/cortex passes the imaging plane within the ROI - the peak in intensity profiles (Fig. 2a-b). We also define a 'fast recovery' for cells that exhibit a near-instantaneous recovery time $(<1 \mathrm{~s})$ (Vid. S1 and S2). Time-lapse images were visually inspected so that only cells that recover fully following the deformation are included in the analysis (Fig. S2) ${ }^{21}$. The majority $(90 \%)$ of untreated HeLa cells $(n=20)$ display a fast recovery, following $1 \mathrm{~min}$ of a $10 \mathrm{nN}$ load. Performing experiments ( $10 \mathrm{nN}$ applied for $1 \mathrm{~min}$ ) while imaging in the most apical region of the cell confirms that the position of the imaging plane does not influence observed dynamics (Fig. S3). In general, the fast recovery dynamics in untreated HeLa cells occur in a manner independent of force magnitude and duration. Therefore, we focus on determining which cellular components are driving the recovery process.

\section{Cytoskeletal influence on shape recovery.}

The cytoskeleton is well-known to largely determine cellular elasticity and morphology ${ }^{22,32-34}$. Here, we examine the role of both actin and microtubules (MTs) immediately following large perturbations. Cells 
were pre-treated with Y-27632, a specific inhibitor of Rho-kinase, Cytochalasin D (CytD) a depolymerizer of actin, and Nocodazole (Noco), a known MT depolymerizer (Fig. S4). Measured strain (Table S3) confirms our earlier findings ${ }^{13}$ that the actin cytoskeleton, not MTs, is necessary for resisting external perturbations. Then, as before, we performed single-plane imaging experiments in order to measure recovery of cells following $1 \mathrm{~min}$ of a $10 \mathrm{nN}$ load.

Fits of intensity profiles to equation (1) reveal that the actin network is the main contributor to the immediate recovery of cells following highly localized loading (Table S2). Box plots reveal variability in characteristic recovery time constants for the various treatments (Fig. 3a-b). In comparison to untreated cells, $\kappa_{1}$ of the membrane is significantly increased for cells treated with $Y-27632$ and CytD $(P<0.05)$, but not for those treated with Noco $(P>0.1)$. This increase in characteristic recovery constants is similarly observed for the cortex, following treatments with $Y-27632$ and CytD $(P<0.001)$, and again are not significantly altered for cells treated with Noco in comparison to untreated cells. Large variance in fits of the secondary recovery constant, $\kappa_{2}$ (movement past the imaging plane), make any significant distinctions between untreated and treated cells undetectable (Fig. 3b). Direct observation of time-lapse images of the membrane demonstrate that the number of cells recovering in $<1 \mathrm{~s}$ dramatically decrease for actindestabilized cells ( $30 \%$ of cells treated with CytD, $n=17$, and $10 \%$ of cells treated with $Y-27632, n=20$ ). Despite large strains (Table S3) and slower recovery upon actin depolymerisation, a large number (50$65 \%$ ) of cells still recover their initial cell shape within minutes following unloading, which leads us to postulate that long-term recovery is largely due to intracellular fluid flow.

Depolymerisation of MTs does not result in considerable differences in recovery constants with untreated HeLa. However, only $60 \%$ of Noco-treated cells recover in $<1 \mathrm{~s}$. We hypothesize that secondary effects of treatment; namely, increased actomyosin contraction may obscure results pertaining to MT depolymerization. Immunofluorescent images demonstrate that tubulin co-localizes with actin following treatment (Fig. S4), which can be attributed to increased stress fibre formation and is a result of GEF-H1 release brought about by activation of RhoA ${ }^{35}$. Therefore, we first inhibited ROCK (the up-regulation of which is associated with stress-fibre formation) with Y-27632, followed by subsequent treatment with Noco. Cells treated with Y-27632+Noco retain visible basal stress fibres, while MTs are completely disrupted and no longer co-localize with fibres (Fig. S6a). The ability of Y-27632+Noco treated cells to recover in < $1 \mathrm{~s}$ is drastically reduced $(20 \%)$, yet diminished strain measured in these cells indicates increased contractility (Table S5), which is likely caused by a short initial incubation time (15 min) with Y27632.

\section{Intracellular pressure contributes to shape recovery.}

Intracellular pressure and interstitial fluid flow may be partially responsible for long-term (> 1s) shape recovery following large deformations. Cytosolic flow within the cell's dense filamentous network has been shown to contribute to initial force relaxation ${ }^{25}$. In order to examine what role cellular pressure and cell volume have on shape recovery, we subjected HeLa cells to hyper- and hypo-osmotic shock conditions with $300 \mathrm{mM}$ of sucrose and $30 \% \mathrm{dH}_{2} \mathrm{O}$ supplemented cell media, respectively. Cells exposed to these conditions were incubated for 10 min prior to performing the experiment to ensure that any transient increase in $\mathrm{Ca}^{2+36}$, as well as any transient volume compensation effects had subsided ${ }^{37}$. A 10 $\mathrm{nN}$ constant force was applied to shocked cells for a 1 min duration followed by subsequent unloading.

Cells exposed to hyper-osmotic shock demonstrate a decrease in volume in comparison to cells in a neutrally osmotic environment, as indicated by a $\sim 58 \%$ decrease in cell height (Table S3). Small blebs are observed on the membrane of these cells in vitro (Fig. 3c). Single-plane imaging of these treated cells was performed as earlier; however, the deformations observed are less distinguishable due to the degradation of fluorescence caused by the addition of the solute. The reduction in deformation and cell 
height (Table S2) correspond with a significant increase in stiffness $(3.8 \pm 1.8 \mathrm{kPa}, \mathrm{n}=7, \mathrm{P}<0.05)$ in comparison to untreated cells $(2.8 \pm 0.7 \mathrm{kPa}, \mathrm{n}=9)$ from the same population. Fits of the intensity curves demonstrate drastically reduced characteristic recovery constants (Fig. 3e, Table S2) for the membrane and cortex of hyper-osmotic cells $\left(P<10^{-4}\right)$. Secondary recovery constants were also reduced indicating slowed movement of the membrane/cortex past the imaging plane (Fig. 3f). Post-processing of recovery images is extremely difficult; however, visible deformations remain, following unloading of the cell (Fig. 3c, $3 \times$ zoom).

On the other hand, cells exposed to hypo-osmotic shock $\left(30 \% \mathrm{dH}_{2} \mathrm{O}\right)$ conditions result in a drastic increase in volume (measured by a $32 \%$ increase in cell height) (Fig. 3d). However, strain is significantly reduced (Table S3), as a result of the increase in incompressible fluid content. Surprisingly, the initial recovery constants of the membrane of cells under hypo-osmotic conditions are significantly reduced in comparison to untreated cells implying slower recovery (Fig. 4e, Table S2). A decrease was also observed between the initial recovery constants of the cortex $(P<0.05$, with outliers removed). There is no statistical difference between hypo- and neutrally osmotic conditions for secondary recovery constants $\left(\kappa_{2}, \mathrm{P}>0.05\right.$ for both membrane and cortex). Only $59 \%$ of hypo-osmotic treated cells recover in $<1 \mathrm{~s}$ following unloading. Young's modulus measurements demonstrate an increase in stiffness for hypoosmotically stressed cells $(3.4 \pm 0.7 \mathrm{kPa}, \mathrm{n}=8, \mathrm{P}=0.05)$. To confirm that intracellular pressure and cytosolic flow positively contribute to the recovery dynamics of HeLa cells, we exposed Y-27632+Noco treated cells to hypo-osmotic shock (Table S5). The increased contractility of Y-27632+Noco treated cells, demonstrated by resistance to deformation and reduced recovery $(20 \%)$, is abolished following osmotic treatment $(80 \%$ recover in $<1 \mathrm{~s})$.

Cellular fluid flow is also controlled and maintained by regulation of pressure (hydrostatic and osmotic) across the plasma membrane. Whether or not the membrane composition itself critically affects the recovery process remains unknown. Here, we employed a cyclic oligosaccharide, methyl- $\beta$-cyclodextrin $(M \beta C D)$ to effectively deplete cholesterol levels of the plasma membrane (Supplementary Methods). While increased stiffness associated with M $\mathrm{BCD}$ treatment has been observed in endothelial cells ${ }^{38}$, AFM force-indentation curves herein reveal a stiffening of $M \beta C D$-treated cells $(E=4.4 \pm 0.8 \mathrm{kPa})$ in comparison to a control group of cells $(E=3.4 \pm 1.3 \mathrm{kPa}$ ), which is a result of increased cellular pressure (Fig. S6b). This increased stiffness corresponds to a decrease in strain of cholesterol depleted cells (Table S5), but did not alter the ability of cells to recover ( $100 \%$ fast recovery for $n=10$ cells).

\section{Viscoelastic model of cell shape recovery.}

Having revealed complex contributions of the cytoskeleton and intracellular pressure in the recovery process, we characterize the viscoelastic contributions of the recovery response. Considering the simultaneous deformation and recovery dynamics of the membrane and cortex, we chose to model them as a single surface. We account for the actin network with a simple elastic model and for the interstitial flows via viscous dissipation. Recovery curves of the membrane/cortex surface displacement $u(\vec{r}, t)$ are thereby modelled using an overdamped $\left(\partial_{t}^{2} u \approx 0\right)$ telegraph equation, containing both elastic $(k)$ and viscous damping $(\mu)$ terms.

$$
\left[\nabla^{2}-\mu \partial_{t}-k\right] u(\vec{r}, t)=0 .
$$

Using this form of the telegraph equation, the displacement of the linked membrane/cortex surface is modeled as a function of the time, $t$, since the AFM tip is retracted and radial distance $r$ from the tip (Fig. 4a). When the membrane/cortex surface is displaced, the viscoelastic inner material attempts to bring the surface to its equilibrium state (prior to deformation). Essentially, the surface is treated as a continuum of infinitesimal elements that are elastically connected to each other and viscoelastically connected to the inner material through a Kelvin-Voigt model, in which viscous dissipation and elastic storage act in 
parallel. Considering that this model assumes overdamped relaxation behaviour, higher order inertia terms are ignored and intensity profiles are estimated from the membrane/cortex dynamics within the ROI (see Supplementary Methods).

Intensity curves from experiments performed on untreated HeLa cells are fit to equation (2) above through the ROI-intensity model. Cells experiencing a 'fast' recovery have a large spring coefficient (high k) and a smaller dissipation coefficient (low $\mu$ ), whereas the reverse is true for slower recovering cells. Alternatively, the dissipation coefficient alone can differ between fast and slow recovering cells. Only fits that correspond with time-lapse images are employed. For fast-recovering cells ( $n=6$ of 8 total), the average spring coefficient $\left(156 \pm 34{\mu \mathrm{m}^{-2}}^{-}\right)$, is greater than the viscous dissipation coefficient $\left(25 \pm 22 \mu \mathrm{m}^{-}\right.$ ${ }^{2}$ ), whereas for slowly recovering cells the reverse is true and the viscous dissipation coefficient (198 \pm 59 $\left.s \cdot \mu \mathrm{m}^{-2}\right)$ is higher than the spring coefficient $\left(33 \pm 22 \mu \mathrm{m}^{-2}\right)$. Repeating the numerical calculation for recovery data following a $20 \mathrm{nN}$ load resulted in no change in mean parameters (Table S4).

Cells treated with cytoskeletal inhibitors, as well as those exposed to hypo-osmotic conditions, are also modelled using equation (2) (Table S4). Although absolute values of individual parameters vary greatly within a given population, $\chi^{2}$ values demonstrate a linear minima between possible values of the parameters $k$ and $\mu$. Hence, a single ratio $\kappa_{r}=k / \mu$, is proposed as sufficient for comparing differences between cells exposed to various treatment conditions (Fig. $4 b$ ). The ratio $\kappa_{r}$ is a rate of recovery constant with units $\mathrm{s}^{-1}$. Using this method again demonstrates that cell-shape recovery of cells treated with $\mathrm{Y}$ 27632 and CytD is significantly $(P<0.05)$ impaired compared to untreated HeLa cells. Numerical modeling demonstrates that cell-shape recovery is dominated by a single recovery constant, largely dependent on the actin cytoskeleton, consistent with our non-linear regression analysis.

\section{Shape recovery in other epithelial cells.}

The remarkable cell-shape recovery observed in HeLa cells begs the question as to whether other noncancerous epithelial cells regain cell-shape in a similar manner. In this light, the deformation/recovery experiment ( $1 \mathrm{~min}$ of $10 \mathrm{nN}$ ) was repeated on MDCK, HEK, and $\mathrm{CHO}$ cells. Experiments were performed on the same day (including HeLa), except for $\mathrm{CHO}$ cells (subsequent experiment), with the same AFM cantilever and calibration techniques. Force indentation measurements reveal comparable Young's moduli across cell types $(E \approx 3 \mathrm{kPa}, \mathrm{P}>0.05)$, cultured on glass. All cell types were cultured to $\sim 90 \%$ confluent monolayers, yet measured heights vary significantly (Fig. 5a, inset). Deformations following 1 min of a $10 \mathrm{nN}$ load, demonstrate that HeLa cells experience significantly greater deformations in comparison to all other cell types examined (Fig. 5a). Strain measured along the axis of loading is significantly greater for HeLa cells in comparison to HEK and MDCK. CHO cells also experience significantly larger strains than MDCK $(P<0.05$, one-way ANOVA, and means comparison with Tukey test). Importantly, all epithelial cells recover their initial shape within minutes following removal of the load. Fits to equation (1) reveal that, MDCK, CHO, and HEK cells recover similar to HeLa (Table S5), with the initial recovery constant dominating the response $\left(\kappa_{1}>\kappa_{2}\right)$. Recovery constants of CHO cells are significantly higher than the other cell types $(P<0.05$, one-way ANOVA). Time-lapse images demonstrate that $100 \%$ of $\mathrm{CHO}$ cells recover in $<1 \mathrm{~s}$. In stark contrast, only a small percentage $(32 \%)$ of HEK cells recover quickly, and none of the MDCK examined $(0 \%)$ recover in $<1 \mathrm{~s}$. Clearly, cell shape recovery is a varied response amongst the epithelial cell types examined here. All of these cells recover their predeformed shape over the long term (within minutes), yet the immediate recovery time constants of this phenomenon are cell-type dependent. 


\section{Discussion}

Significant shape changes are pervasive during the life cycle of a cell and are consequent of both internal and external forces that arise during events such as cell-cell communication, motility, and tissue-level strain ${ }^{1}$. In response to these mechanical signals, cells have been shown to quickly alter their morphology, while maintaining their structural integrity $4,21,30$. That being said, the mechanisms behind this extraordinary ability of cells to actively respond to mechanical cues are largely unknown. Only a limited number of studies have examined shape recovery mechanisms ${ }^{30}$, with most inferring recovery from cantilever deflection data, as in stress-relaxation experiments ${ }^{14-17}$. Here, we developed a direct visual method using a traditional LSCM set-up involving time-lapse imaging to interpret the recovery times of HeLa cells following AFM mechanical stimulation. Fluorescence intensity measurements were used to characterize the response of HeLa membrane and cortex immediately, during, and following both short (seconds) and long (minutes) durations of loading. Surprisingly, the coupled membrane/cortex (Fig. S1) result in near-instantaneous cell-shape recovery $(<1 \mathrm{~s})$ in the majority of cells $(90 \%)$, regardless of load magnitude and duration (Fig. 2c, Table S1). This method allows us to examine and characterize the contributions from the actin and MT cytoskeleton, as well as effects from changes in osmolality.

Elastic and viscous components of the cell have been previously shown to heavily rely upon actin organization, without significant dependence on MTs ${ }^{39}$. Recent observations have shown that neither MTs nor keratin intermediate filaments affect cellular rheology ${ }^{25}$. However, MTs have been shown to transmit forces from the apical cell membrane, causing stress fibre deformation in the basal plane of fibroblasts ${ }^{14}$. Moreover, recovery of chondrocytes following compression has been shown to rely on MTs ${ }^{30}$. Here, in the absence of intact MTs, Noco-treated HeLa do not present a significant change from the recovery dynamics observed in untreated cells (Fig. 3a,b, Table S2). We postulate that effects caused by Noco treatment could be obscured, since tubulin has been shown to redistribute to surrounding stress fibre adhesion sites in HeLa cells ${ }^{35}$. Immunofluorescent images confirm that tubulin co-localizes with actin following treatment (Fig. S4). Therefore, we first inhibited ROCK with Y-27632, for a group of cells. Cells treated with Y-27632+Noco still appear to possess a large number of actin stress fibres in the basal plane, but MTs are completely disrupted (Fig. S6). However, the ability of Y-27632+Noco treated cells to recover quickly is drastically reduced $(20 \%)$. One explanation could be attributed to cofilin regulation. In particular, actin depolymerizing factor (ADF)/cofilin has been shown to inhibit myosin II binding to F-actin, thereby regulating actomyosin assembly and contractile stress generation ${ }^{40}$. In particular, increased actomyosin II assembly and activity has been observed following depletion of cofilin in HeLa cells ${ }^{40}$. Considering that the inhibition of ROCK with Y-27632 has been shown to increase cofilin phosphorylation in esophageal squamous cancer cells ${ }^{41}$, it is possible that pre-treatment here results in an accumulation of cortical F-actin. Increased phosphorylation of cofilin leads to an accumulation of actin filaments resulting in an overly contractile cortex ${ }^{42}$, which can account for the observed increase in resistance to deformation and slowed recovery.

Actin is well-known to resist external perturbations ${ }^{21,14,39}$, and our results now provide strong evidence that cortical actin is a key regulator in cell shape recovery processes. Inhibition of HeLa with CytD and Y27632 leads to significantly slower recovery (Fig. 3a). The ROCK pathway in particular, plays a considerable role in the recovery process, demonstrating an $80 \%$ decrease in "fast" recovering cells. Considering that ROCK inhibition effects myosin light chain downstream (by inhibiting phosphorylation), it is not surprising that contractility of the cortex is reduced, as has been shown during cytokinesis ${ }^{43}$. Reduced contractility of the cortex corresponds with the larger deformations observed (Table S3), and may account for the slower recovery dynamics (Tables S2). It is necessary to highlight that whether an overly-contractile or reduced-contractile cortex, or both, results in slower recovery remains an open question. Active tension alone is insufficient for cell volume control ${ }^{32,44}$, but instead relies on 
contributions from osmotic and hydrostatic pressure, as has been shown during bleb formation ${ }^{45}$ and mitosis $^{46}$.

Increases in osmotic pressure increase cell volume, the hydrostatic pressure difference across the membrane, as well as cortical stress. Here, exposure of cells to hyper- and hypo-osmotic conditions demonstrates intracellular pressure as crucial for cell-shape recovery following mechanical perturbations, in agreement with current poroelastic models ${ }^{25}$ and our viscoelastic recovery membrane/cortex model. Hyper-osmotic shock leads to a significant decrease in cell height, deformation, and recovery (Table S2 and S3), which agrees with previous reports of reduced elasticity, and increased viscous properties ${ }^{47}$. In contrast, hypo-osmotic conditions demonstrate increased cell volume, without significantly altering the recovery dynamics of untreated HeLa (Fig. 3e,f). In fact, the percentage of cells that recover quickly (< $1 \mathrm{~s}$ ) is reduced to $56 \%$ for hypo-osmotic stressed cells in comparison to $90 \%$ for neutrally osmotic cells. It is possible that the reduction in 'fast' recovering cells is due to active contractility of the cortex in response to volume changes. In situ models have also shown complex dynamics of mechanosensitive channels in response AFM deformation, resulting from cortical tension and osmotic pressure regulation ${ }^{44}$. Overall, intracellular pressure positively contributes to cell shape recovery. Hypo-osmotic shock regains the fast recovery dynamics of $\mathrm{Y}-27632+$ Noco treated cells $(80 \%$ in $<1 \mathrm{~s}$, compared to $20 \%$ for osmotically neutral). Intracellular fluid flow has been shown to contribute to stress relaxation ${ }^{25}$; however, our results suggest that there may be an upper limit on intracellular pressure that reduces the speed of cell shape recovery.

We previously demonstrated that various membrane-bound dyes stiffen the membrane without affecting the deformability of HeLa cells, or long-term recovery of cell shape ${ }^{21}$. Here, rather than inserting a marker, we employ M $B C D$ to deplete cholesterol levels of the plasma membrane. Treatment with M $B C D$ has previously been shown to decrease cholesterol levels significantly (upwards of $50 \%$ ) ${ }^{38}$. Considering the membrane and cortex are directly linked by proteins, such as ezrin, radixin, and moesin (ERM) ${ }^{48}$, it is unsurprising that cholesterol depletion alone does not cause a considerable change in deformation or recovery dynamics. Due to the low solubility of $M \beta C D$, it is likely that intracellular pressure contributed to the increase in stiffness observed (Fig. S6). An interplay of membrane and cortex dynamics affect both cell shape and function ${ }^{49,50}$, and so they must be decoupled in future studies in order to examine their respective contributions to the recovery process.

To characterize the mechanics of recovery, a continuous viscoelastic model is implemented herein. Treating the cell membrane/cortex as a continuum of viscoelastic elements reveals that recovery is dominated by a single rate of recovery constant (Fig. 4). This implies a single dominant mechanism is involved in cell shape recovery - obscured by our linear regression analysis with two separate recovery rates (Fig. 2a-b). Our model shows the most success at simulating slow recovery, and is less successful when dealing with near-instantaneous recovery (Fig. 2a); a similar challenge faced using linear regression on nearly discontinuous data. Fast AFM indentation speeds (10 $\mu \mathrm{m} / \mathrm{s}$, employed herein) have been correlated with conserved cell volume ${ }^{51}$, which justifies the use of a single membrane/cortex model, neglecting pressure, to represent recovery behaviour. While limited in its predictive capabilities, our model confirms that a large viscous dissipation coefficient is associated with actin destabilized cells (particularly Y-27632). The model suggests a bulk elastic behaviour drives the fast shape recovery of HeLa cells following local deformations. The various active cellular processes contributing to the recovery mechanism cannot be decoupled by the model in its current form. Recently, Jiang et al. incorporated flow of cytosol, mechanically sensitive ion channels and active cortical tension in a mathematical model that could predict cell volume and pressure under different conditions (including AFM deformation). Their results demonstrated a complex interplay between cortical tension and osmotic pressure, where slow deformation on the order of $\mu \mathrm{m} / \mathrm{min}$ is dominated by permeation of water ${ }^{44}$. Additional complexities, such 
as those used to model the deformation mechanics, must be considered to adequately model cell-shape recovery as well.

Here, we reveal cell-shape recovery as a rapid, viscoelastic response in epithelial cells. This often overlooked phenomenon is typically examined during compression of chondrocytes and erythrocytes ${ }^{28-30}$; cells that behave vastly different than epithelia. Here, HeLa recover from relatively large strains ( 60\%) (Fig. 5a), in contrast to chondrocytes, which have been previously shown to succumb to a much lower critical strain threshold $(\sim 30 \%)^{29}$ despite their continuous compression cycles in vivo. Moreover, HeLa, a cancerous cell line, recover their cell-shape near-instantaneously, while other non-cancerous cell types (CHO, HEK, MDCK) recover with varied rates (Fig. 5). Whether, or not, the rapid recovery rates of HeLa result from pathologic gene expression remains to be seen. Compression has been shown to result in an increased migratory response of cancer cells ${ }^{52}$. While presumptive, we postulate that fast recovering HeLa may be primed for cell-shape recovery from processes like intra- and extravasation. Further characterization of the mechanisms underlying cell-shape recovery processes are important and necessary, and may unveil changes brought about by diseased states.

Our work highlights the need for investigation into the cell-shape recovery behaviour of a variety of normal and pathological cell models. Large elastic coefficients from our model can account for the rapid recovery of HeLa; however, differences in recovery times between cell types must be further investigated. Importantly, for HeLa, it is shown that load magnitude and duration do not affect the speed of recovery. Organization and contractility of the cortex appear to be critically linked to osmotic pressure in cell-shape recovery processes, as indicated by a severe reduction in fast-recovering cells following cytoskeletal disruption of actin, and under osmotic-shock conditions.

\section{Competing Financial Interests}

The authors declare no competing interests.

\section{Author Contributions}

$\mathrm{KH}$ and AEP designed the experiments; $\mathrm{KH}$ performed and analyzed the experimental research. TNS designed and implemented the model. $\mathrm{KH}$ wrote the paper with contributions from AEP and TNS.

\section{Acknowledgments}

$\mathrm{KH}$ would like to thank Dr. NV Bukoreshtliev for his enthusiasm and insightful suggestions, and Dr. M Bertrand for valuable discussions.

\section{Funding}

AEP was supported by the Canada Research Chairs (CRC) program and a Province of Ontario Early Researcher Award. This work was supported by a Natural Sciences and Engineering Research Council (NSERC) Discovery Grant, an NSERC Discovery Accelerator Supplement, a CRC Operating Grant and the Canadian Foundation for Innovation Leaders Opportunity Fund. We acknowledge funding from ERC Advanced Grant 291234 MiCE and EMBO funding ALTF181-2013 to TNS. 


\section{References}

1. N. V. Bukoreshtliev, K. Haase and A. E. Pelling, Cell Tissue Res, 2013, 352, 77-94.

2. B. D. Hoffman and J. C. Crocker, Annu Rev Biomed Eng, 2009, 11, 259-288.

3. D. Stamenovic, N. Rosenblatt, M. Montoya-Zavala, B. D. Matthews, S. Hu, B. Suki, N. Wang and D. E. Ingber, Biophys J, 2007, 93, L39-L41.

4. D. A. Fletcher and P. L. Geissler, Annu Rev Phys Chem, 2009, 60, 469-486.

5. T. G. Kuznetsova, M. N. Starodubtseva, N. I. Yegorenkov, S. A. Chizhik and R. I. Zhdanov, Micron, 2007, 38, 824-833.

6. R. E. Mahaffy, C. K. Shih, F. C. MacKintosh and J. Kas, Phys Rev Lett, 2000, 85, 880-883.

7. M. Radmacher, M. Fritz, C. M. Kacher, J. P. Cleveland and P. K. Hansma, Biophys J, 1996, 70, 556567.

8. R. E. Mahaffy, S. Park, E. Gerde, J. Kas and C. K. Shih, Biophys J, 2004, 86, 1777-1793.

9. L. Guolla, M. Bertrand, K. Haase and A. E. Pelling, J Cell Sci, 2012, 125, 603-613.

10. O. Chaudhuri, S. H. Parekh, W. A. Lam and D. A. Fletcher, Nat Methods, 2009, 6, 383-U392.

11. D. Kirmizis and S. Logothetidis, Int J Nanomed, 2010, 5, 137-145.

12. Q. S. Li, G. Y. H. Lee, C. N. Ong and C. T. Lim, Biochem Bioph Res Co, 2008, 374, 609-613.

13. K. Haase and A. E. Pelling, Communicative and Integrative Biology, 2013, 6.

14. E. M. Darling, M. Topel, S. Zauscher, T. P. Vail and F. Guilak, J Biomech, 2008, 41, 454-464.

15. E. M. Darling, S. Zauscher and F. Guilak, Osteoarthr Cartilage, 2006, 14, 571-579.

16. S. Moreno-Flores, R. Benitez, M. D. Vivanco and J. L. Toca-Herrera, Nanotechnology, 2010, 21.

17. H. W. Wu, T. Kuhn and V. T. Moy, Scanning, 1998, 20, 389-397.

18. E. H. Zhou, X. Trepat, C. Y. Park, G. Lenormand, M. N. Oliver, S. M. Mijailovich, C. Hardin, D. A. Weitz, J. P. Butler and J. J. Fredberg, P Natl Acad Sci USA, 2009, 106, 10632-10637.

19. P. Kollmannsberger and B. Fabry, Annu Rev Mater Res, 2011, 41, 75-97.

20. W. R. Trickey, F. P. T. Baaijens, T. A. Laursen, L. G. Alexopoulos and F. Guilak, J Biomech, 2006, $39,78-87$.

21. K. Haase and A. E. Pelling, Cytoskeleton (Hoboken), 2013, 70, 494-514.

22. G. Salbreux, G. Charras and E. Paluch, Trends Cell Biol, 2012, 22, 536-545.

23. J. Berro, A. Michelot, L. Blanchoin, D. R. Kovar and J. L. Martiel, Biophys J, 2007, 92, 2546-2558.

24. M. P. Murrell and M. L. Gardel, P Natl Acad Sci USA, 2012, 109, 20820-20825. 
25. E. Moeendarbary, L. Valon, M. Fritzsche, A. R. Harris, D. A. Moulding, A. J. Thrasher, E. Stride, L. Mahadevan and G. T. Charras, Nat Mater, 2013, 12, 253-261.

26. V. Lulevich, T. Zink, H. Y. Chen, F. T. Liu and G. Y. Liu, Langmuir, 2006, 22, 8151-8155.

27. J. Alcaraz, L. Buscemi, M. Grabulosa, X. Trepat, B. Fabry, R. Farre and D. Navajas, Biophys J, 2003, 84, 2071-2079.

28. J. P. Shelby, J. White, K. Ganesan, P. K. Rathod and D. T. Chiu, Proceedings of the National Academy of Sciences, 2003, 100, 14618-14622.

29. A. C. Shieh, E. J. Koay and K. A. Athanasiou, Biomech Model Mechan, 2006, 5, 172-179.

30. G. Ofek, D. C. Wiltz and K. A. Athanasiou, Biophys J, 2009, 97, 1873-1882.

31. P. Bursac, G. Lenormand, B. Fabry, M. Oliver, D. A. Weitz, V. Viasnoff, J. P. Butler and J. J. Fredberg, Nat Mater, 2005, 4, 557-561.

32. R. McBeath, D. M. Pirone, C. M. Nelson, K. Bhadriraju and C. S. Chen, Dev Cell, 2004, 6, 483-495.

33. S. Kumar, I. Z. Maxwell, A. Heisterkamp, T. R. Polte, T. P. Lele, M. Salanga, E. Mazur and D. E. Ingber, Biophys J, 2006, 90, 3762-3773.

34. M. A. Wozniak and C. S. Chen, Nat Rev Mol Cell Bio, 2009, 10, 34-43.

35. Y. C. Chang, P. Nalbant, J. Birkenfeld, Z. F. Chang and G. M. Bokoch, Mol Biol Cell, 2008, 19, 21472153.

36. G. R. Erickson, D. L. Northrup and F. Guilak, Osteoarthr Cartilage, 2003, 11, 187-197.

37. E. K. Hoffmann and P. B. Dunham, Int Rev Cytol, 1995, 161, 173-262.

38. F. J. Byfield, H. Aranda-Espinoza, V. G. Romanenko, G. H. Rothblat and I. Levitan, Biophys J, 2004, 87, 3336-3343.

39. A. N. Ketene, P. C. Roberts, A. A. Shea, E. M. Schmelz and M. Agah, Integr Biol-Uk, 2012, 4, 540549.

40. O. Wiggan, A. E. Shaw, J. G. DeLuca and J. R. Bamburg, Dev Cell, 2012, 22, 530-543.

41. L. L. Wang, L. X. Xue, H. X. Yan, J. Li and Y. C. Lu, Mol Biol Rep, 2010, 37, 1971-1977.

42. S. Arber, F. A. Barbayannis, H. Hanser, C. Schneider, C. A. Stanyon, O. Bernard and P. Caroni, Nature, 1998, 393, 805-809.

43. H. Kosako, T. Yoshida, F. Matsumura, T. Ishizaki, S. Narumiya and M. Inagaki, Oncogene, 2000, 19, 6059-6064.

44. H. Y. Jiang and S. X. Sun, Biophys J, 2013, 105, 609-619.

45. J. Y. Tinevez, U. Schulze, G. Salbreux, J. Roensch, J. F. Joanny and E. Paluch, P Natl Acad Sci USA, 2009, 106, 18581-18586. 
46. M. P. Stewart, J. Helenius, Y. Toyoda, S. P. Ramanathan, D. J. Muller and A. A. Hyman, Nature, 2011, 469, 226-230.

47. G. Guigas, C. Kalla and M. Weiss, Biophys J, 2007, 93, 316-323.

48. P. Kunda, A. E. Pelling, T. Liu and B. Baum, Curr Biol, 2008, 18, 91-101.

49. J. Saarikangas, H. X. Zhao and P. Lappalainen, Physiol Rev, 2010, 90, 259-289.

50. G. T. Charras, C. K. Hu, M. Coughlin and T. J. Mitchison, J Cell Biol, 2006, 175, 477-490.

51. A. R. Harris and G. T. Charras, Nanotechnology, 2011, 22.

52. J. M. Tse, G. Cheng, J. A. Tyrrell, S. A. Wilcox-Adelman, Y. Boucher, R. K. Jain and L. L. Munn, $P$ Natl Acad Sci USA, 2012, 109, 911-916.

\section{Figure Legends}

Figure 1 | Measuring the dynamics of deformation and recovery.

a, Schematic of the experimental setup and procedure. Volume-images of an undeformed cell are acquired using LSCM, followed by setting the imaging plane to $f \sim 2 \mu \mathrm{m}$ below the upper surface of the membrane and subsequent time-lapse imaging. (i) The AFM tip deforms the membrane above the nucleus with a set force magnitude. As the tip approaches and deforms the cell, time-lapse images result in decreased fluorescence within the imaging plane (in an ROI where the deformation is visible). (ii) For recovery experiments, the tip is retracted from the cell following a specified duration of constant force. Corresponding depictions of intensity over time measured from an ROI are shown. In the case of initial deformation, the initial fluorescence intensity observed from the EGFP-tagged membrane (normalized to 1) diminishes as it is deformed and moves below the imaging plane. For recovery experiments, the membrane is initially deformed when continuous imaging begins. At the outset there is a diminished fluorescence signal within the ROI (normalized to 0), followed by an increase in intensity following tip retraction. b, Z-projection and orthogonal views of an untreated HeLa cell prior-to and undergoing $10 \mathrm{nN}$ of force. The imaging plane for subsequent continuous imaging following load removal is shown. $\mathbf{c}, \mathrm{XY}-$ images from the time-lapse following load removal are shown, corresponding to the same cell in $\mathbf{b}$. Shown is the cell just prior to and just after tip retraction. Arrows indicate the small ROI. Scale bars are 10 $\mu \mathrm{m}$.

Figure 2 | Recovery of HeLa cells is near-instantaneous.

a-b, Recovery curves are shown following retraction of the AFM tip ( $\mathrm{t}=0)$. In $\mathbf{a}$, a typical curve for HeLa cells is shown where the peak intensity occurs in $<1 \mathrm{~s}$. In a small $(10 \%)$ number of untreated cells a much slower recovery time is observed, as in b. c-d, Box plots of characteristic recovery rate constants $\left(\kappa_{1}\right.$ and $\kappa_{2}$ ) from fits of recovery curves as shown in $\mathbf{a}$ and $\mathbf{b}$ to (1) are shown. Box plots shown are $25^{\text {th }}$, $75^{\text {th }}$ percentiles. Squares indicate mean values, and outlier data (1.5-fold) is indicated by plus signs $(+)$. Recovery constants shown are for recovery curves following $15 \mathrm{~s}$ (black), $1 \mathrm{~min}$ (blue) and $10 \mathrm{~min}$ (red) durations of a $10 \mathrm{nN}$ (open boxes) and $20 \mathrm{nN}$ (shaded boxes) load. No significant difference load magnitudes or durations ( $P>0.05$, using paired t-tests). Mean values across all experiments is indicated by a dashed line for both $\kappa_{1}$ and $\kappa_{2}$.

Figure 3 | Actin and osmotic pressure are major contributors to recovery. 
a-b, Box plots of characteristic time constants are shown for fits of membrane recovery of untreated HeLa (black), and cells treated with CytD (red), Y-27632 (green), and Noco (blue). Recovery constants ( $\kappa_{1}$ and $\kappa_{2}$ ) shown are for recovery curves following 1 min of a $10 \mathrm{nN}$ load. In $\mathbf{b}$, there is no significance, even with removal of outliers. c-d, LSCM Z-projection images are shown with corresponding orthogonal projections prior to $(t=0)$, during $(t=1 \mathrm{~min})$ and a red (undeformed) / green (deformed) overlay following load removal $(\mathrm{t}=3 \mathrm{~min})$. c, Hyper-osmotic treatment with $300 \mathrm{mM}$ sucrose. Outset, arrow indicates remaining deformed membrane. d, Hypo-osmotic treatment with $30 \% \mathrm{dH}_{2} \mathrm{O}$. e-f, Box plots of characteristic recovery constants from membrane fits of osmotic-treated cell experiments are shown. Recovery constants shown are for recovery curves following $1 \mathrm{~min}$ of a $10 \mathrm{nN}$ load. All box plots shown are $25^{\text {th }}, 75^{\text {th }}$ percentiles. Squares indicate mean values, and outlier data $(1.5$-fold $)$ is indicated by plus signs $(+)$. Astrisks $\left(^{*}\right)$ indicate significant differences with respect to untreated cells $(P<0.05$, using paired t-tests).

\section{Figure 4 | Mechanical characterization of recovery.}

a, Schematic of the proposed viscoelastic mechanical model. b. Plot of time constants derived from equation (2). Astrisks $\left({ }^{*}\right)$ indicate a significant difference compared to untreated cells $(P<0.05$, using paired t-tests). Error bars represent the standard deviation.

Figure 5 | Epithelial cells recover shape following loading.

a, Plots of axial strain are shown for HeLa (black), MDCK (red), HEK (green), and CHO (blue) cells. Inset, Initial height $\left(\mathrm{h}_{\mathrm{o}}\right)$ and deformation $(\mathrm{u})$ following $1 \mathrm{~min}$ of $10 \mathrm{nN}$ load. b. Plot of initial characteristic recovery constants, $\kappa_{1}$. Astrisks $\left({ }^{*}\right)$ indicate a significant difference between $\mathrm{CHO}$ and all other cell types $(\mathrm{P}<0.05$, paired t-test). Error bars represent the standard deviation. 

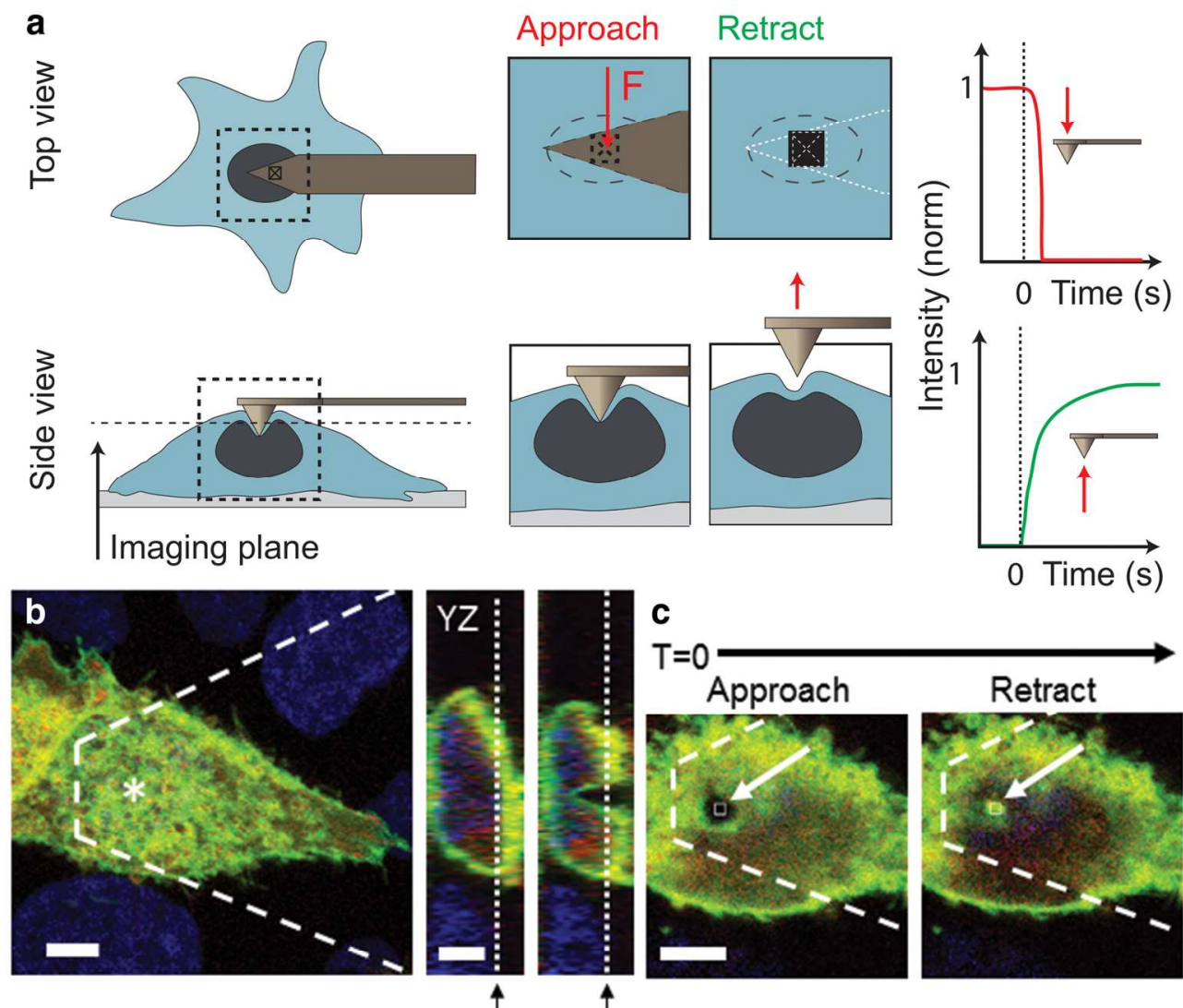

Imaging plane

Figure 1 | Measuring the dynamics of deformation and recovery.

a, Schematic of the experimental setup and procedure. Volume-images of an undeformed cell are acquired using LSCM, followed by setting the imaging plane to $f \sim 2 \mu \mathrm{m}$ below the upper surface of the membrane and subsequent time-lapse imaging. (i) The AFM tip deforms the membrane above the nucleus with a set force magnitude. As the tip approaches and deforms the cell, time-lapse images result in decreased fluorescence within the imaging plane (in an ROI where the deformation is visible). (ii) For recovery experiments, the tip

is retracted from the cell following a specified duration of constant force. Corresponding depictions of intensity over time measured from an ROI are shown. In the case of initial deformation, the initial

fluorescence intensity observed from the EGFP-tagged membrane (normalized to 1 ) diminishes as it is deformed and moves below the imaging plane. For recovery experiments, the membrane is initially deformed when continuous imaging begins. At the outset there is a diminished fluorescence signal within the

ROI (normalized to 0 ), followed by an increase in intensity following tip retraction. b, Z-projection and orthogonal views of an untreated HeLa cell prior-to and undergoing $10 \mathrm{nN}$ of force. The imaging plane for subsequent continuous imaging following load removal is shown. $\mathrm{C}, \mathrm{XY}$-images from the time-lapse following load removal are shown, corresponding to the same cell in b. Shown is the cell just prior to and just after tip retraction. Arrows indicate the small ROI. Scale bars are $10 \mu \mathrm{m}$.

Fig. 1

$148 \times 131 \mathrm{~mm}(300 \times 300$ DPI $)$ 
a

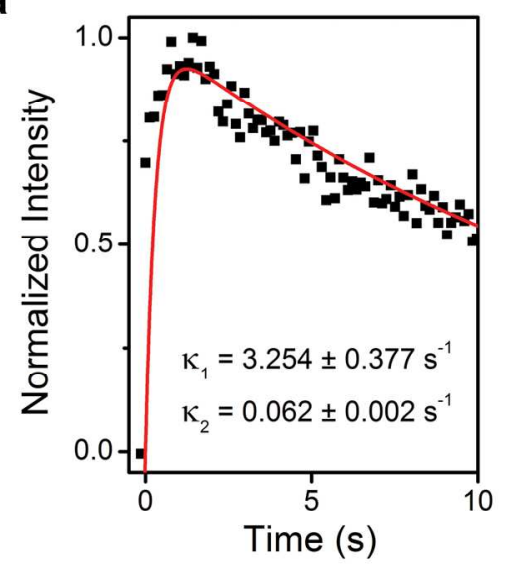

b

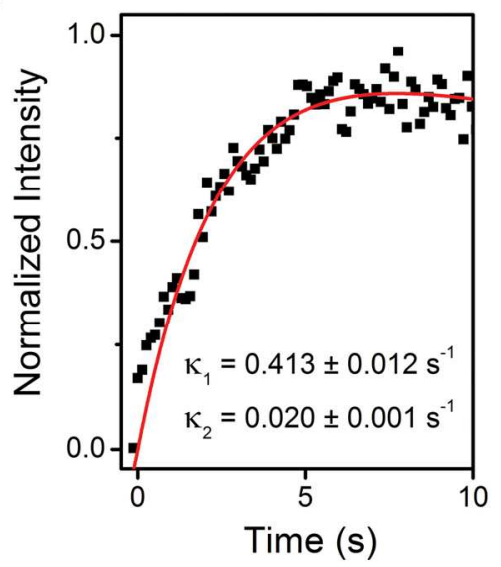

C

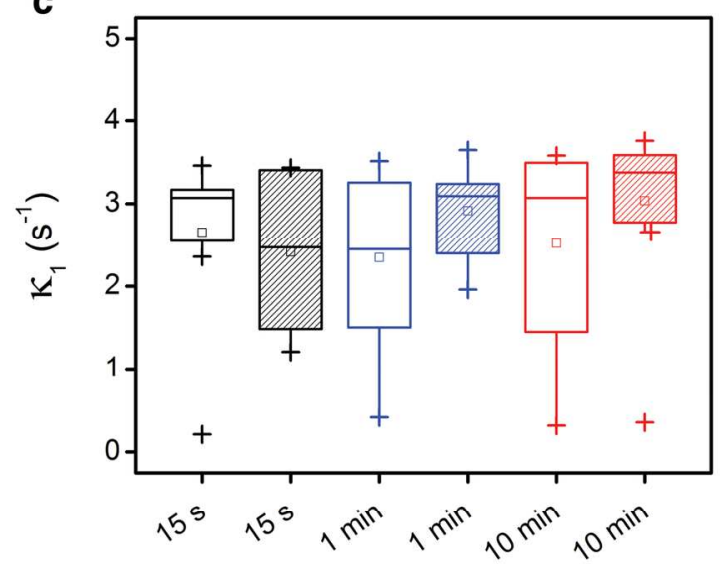

d

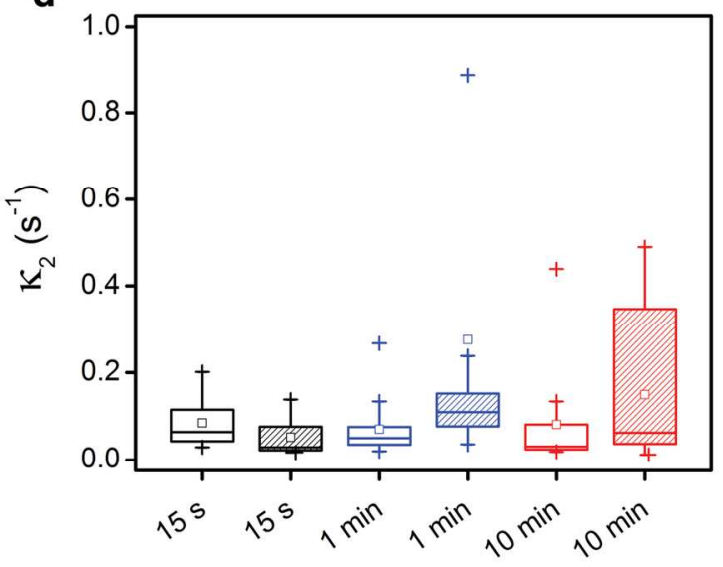

Figure 2 | Recovery of HeLa cells is near-instantaneous.

$a-b$, Recovery curves are shown following retraction of the AFM tip $(t=0)$. In $a$, a typical curve for HeLa cells is shown where the peak intensity occurs in $<1 \mathrm{~s}$. In a small $(10 \%)$ number of untreated cells a much slower recovery time is observed, as in b. c- $d$, Box plots of characteristic recovery rate constants ( $k 1$ and $\mathrm{k} 2$ ) from fits of recovery curves as shown in $a$ and $b$ to (1) are shown. Box plots shown are 25th, 75th percentiles. Squares indicate mean values, and outlier data $(1.5-$ fold $)$ is indicated by plus signs $(+)$. Recovery constants shown are for recovery curves following $15 \mathrm{~s}$ (black), $1 \mathrm{~min}$ (blue) and $10 \mathrm{~min}$ (red) durations of a $10 \mathrm{nN}$ (open boxes) and $20 \mathrm{nN}$ (shaded boxes) load. No significant difference load magnitudes or durations ( $P>0.05$, using paired t-tests). Mean values across all experiments is indicated by a dashed line for both $\mathrm{k} 1$ and $\mathrm{k} 2$.

Fig. 2

$157 \times 148 \mathrm{~mm}(300 \times 300$ DPI $)$ 
a

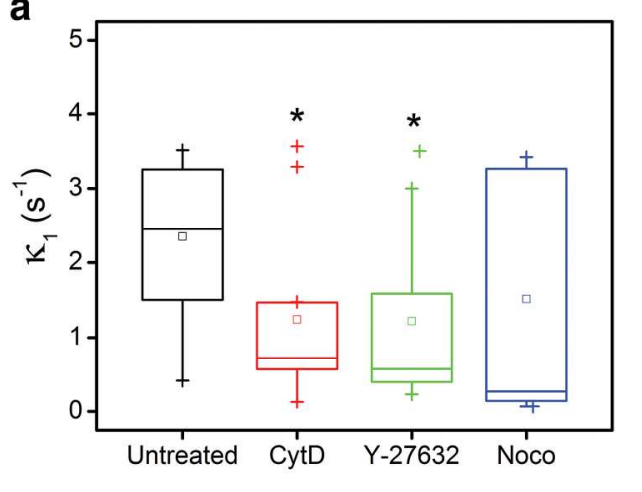

b

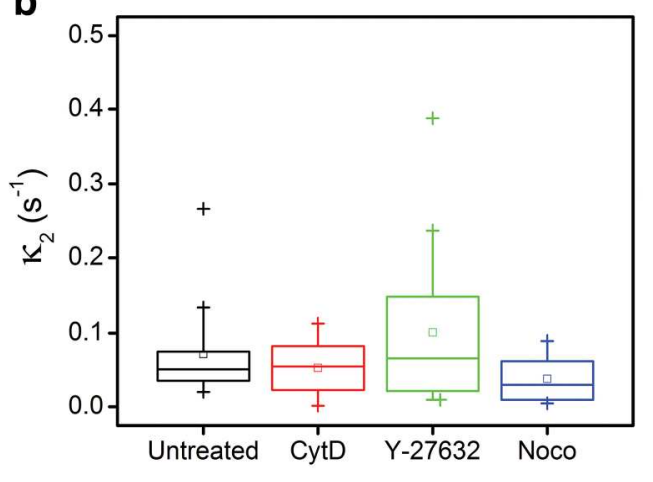

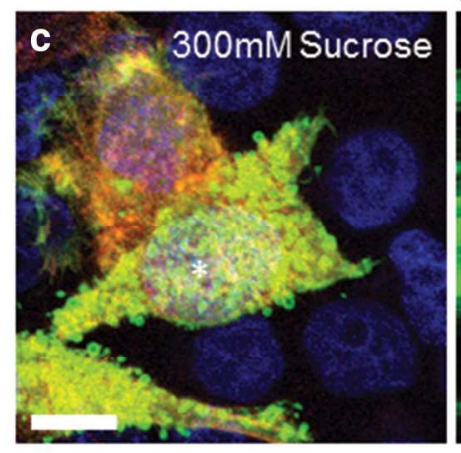

$t=0 \quad t=1 \quad t=3$

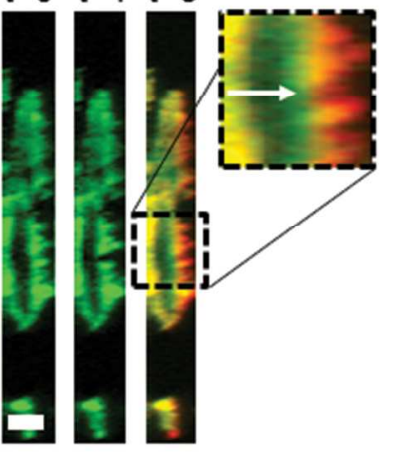

d

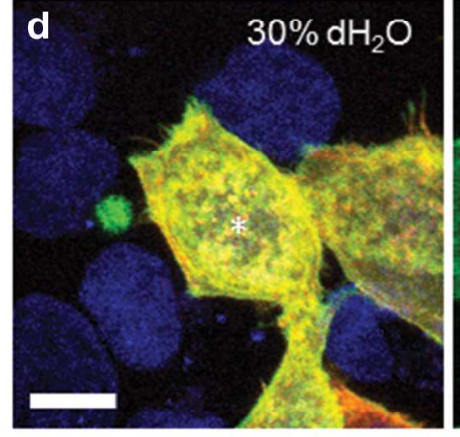

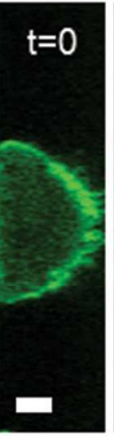

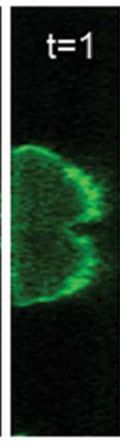

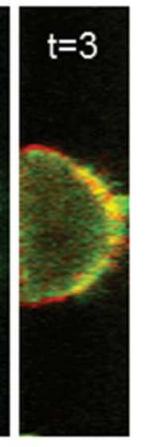
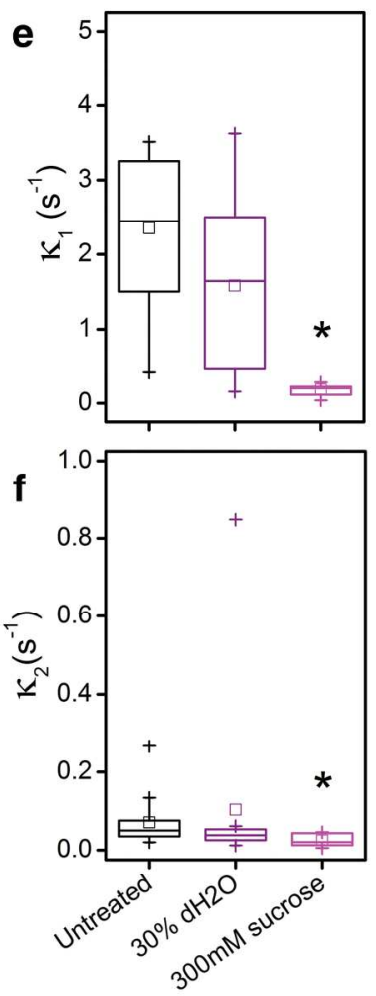

Figure $3 \mid$ Actin and osmotic pressure are major contributors to recovery.

$a-b$, Box plots of characteristic time constants are shown for fits of membrane recovery of untreated HeLa (black), and cells treated with CytD (red), Y-27632 (green), and Noco (blue). Recovery constants ( $\mathrm{k} 1$ and $\mathrm{k} 2$ ) shown are for recovery curves following $1 \mathrm{~min}$ of a $10 \mathrm{nN}$ load. In b, there is no significance, even with removal of outliers. c-d, LSCM Z-projection images are shown with corresponding orthogonal projections prior to $(\mathrm{t}=0)$, during ( $\mathrm{t}=1 \mathrm{~min}$ ) and a red (undeformed) / green (deformed) overlay following load removal ( $\mathrm{t}=3 \mathrm{~min})$. c, Hyper-osmotic treatment with $300 \mathrm{mM}$ sucrose. Outset, arrow indicates remaining deformed membrane. d, Hypo-osmotic treatment with 30\% dH2O. e-f, Box plots of characteristic recovery constants from membrane fits of osmotic-treated cell experiments are shown. Recovery constants shown are for recovery curves following $1 \mathrm{~min}$ of a $10 \mathrm{nN}$ load. All box plots shown are 25th, 75th percentiles. Squares indicate mean values, and outlier data $(1.5$-fold $)$ is indicated by plus signs $(+)$. Astrisks (*) indicate significant differences with respect to untreated cells $(P<0.05$, using paired t-tests).

Fig. 3 
$195 \times 236 \mathrm{~mm}(300 \times 300 \mathrm{DPI})$ 


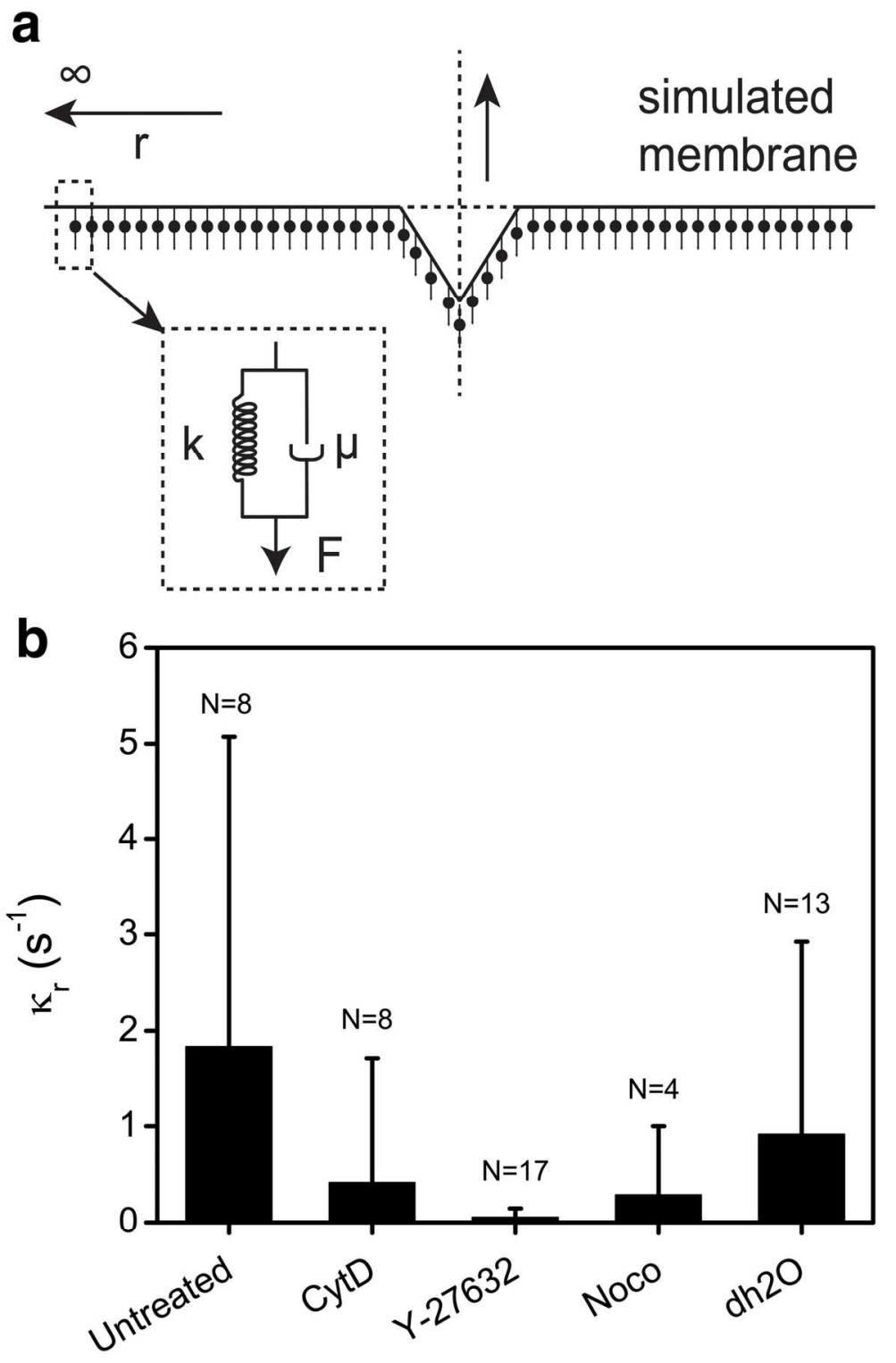

Figure 4 | Mechanical characterization of recovery.

a, Schematic of the proposed viscoelastic mechanical model. b, Plot of time constants derived from equation (2). Astrisks $(*)$ indicate a significant difference compared to untreated cells $(P<0.05$, using paired $t-$ tests). Error bars represent the standard deviation.

Fig. 4

$126 \times 194 \mathrm{~mm}(300 \times 300 \mathrm{DPI})$ 

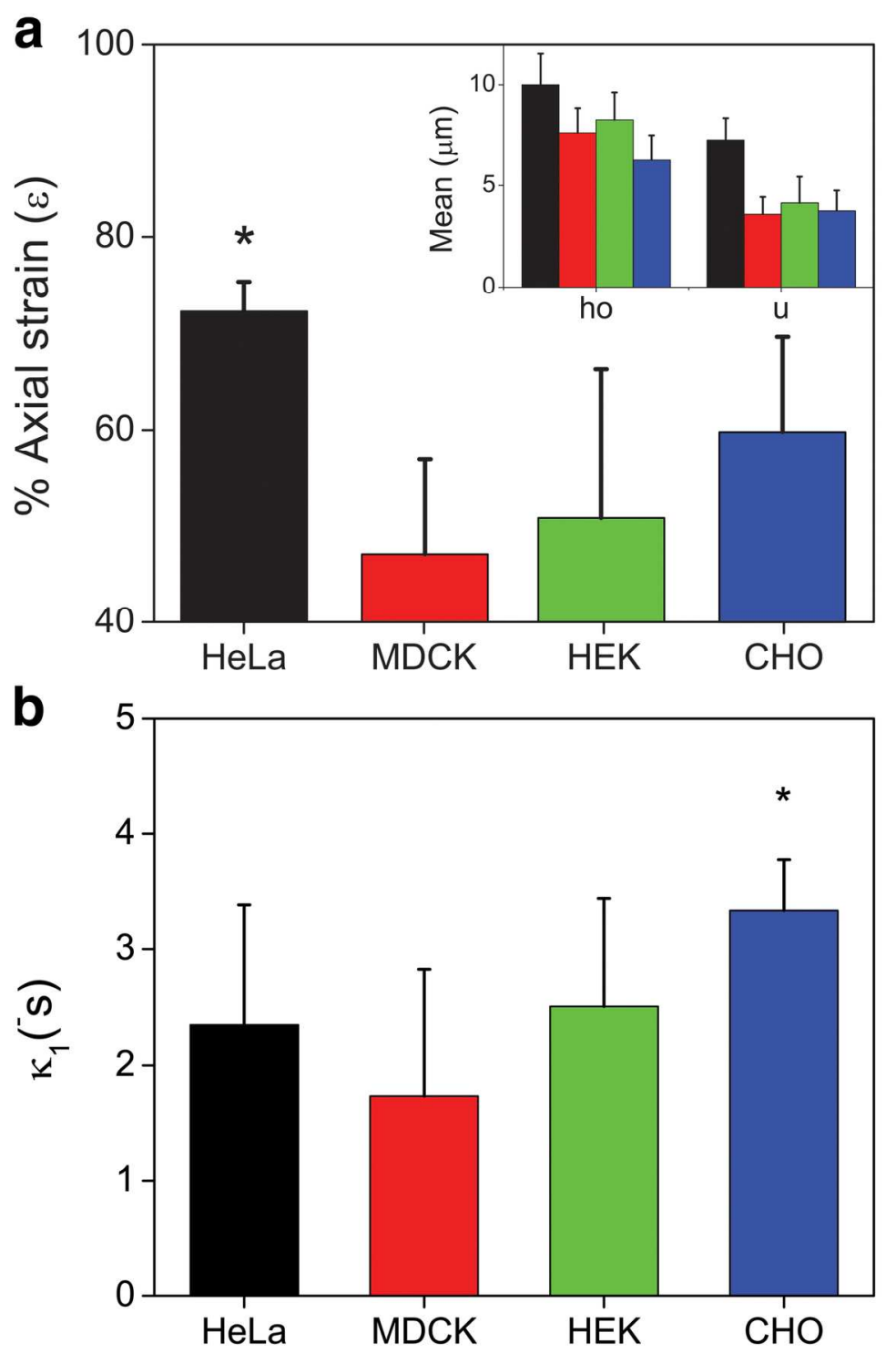

Figure 5 | Epithelial cells recover shape following loading. a, Plots of axial strain are shown for HeLa (black), MDCK (red), HEK (green), and CHO (blue) cells. Inset, Initial height (ho) and deformation (u) following $1 \mathrm{~min}$ of $10 \mathrm{nN}$ load. b, Plot of initial characteristic recovery constants, $\mathrm{k} 1$. Astrisks $(*)$ indicate a significant difference between $\mathrm{CHO}$ and all other cell types $(\mathrm{P}<0.05$, paired t-test). Error bars represent the standard deviation.

Fig. 5

$128 \times 199 \mathrm{~mm}(300 \times 300 \mathrm{DPI})$ 

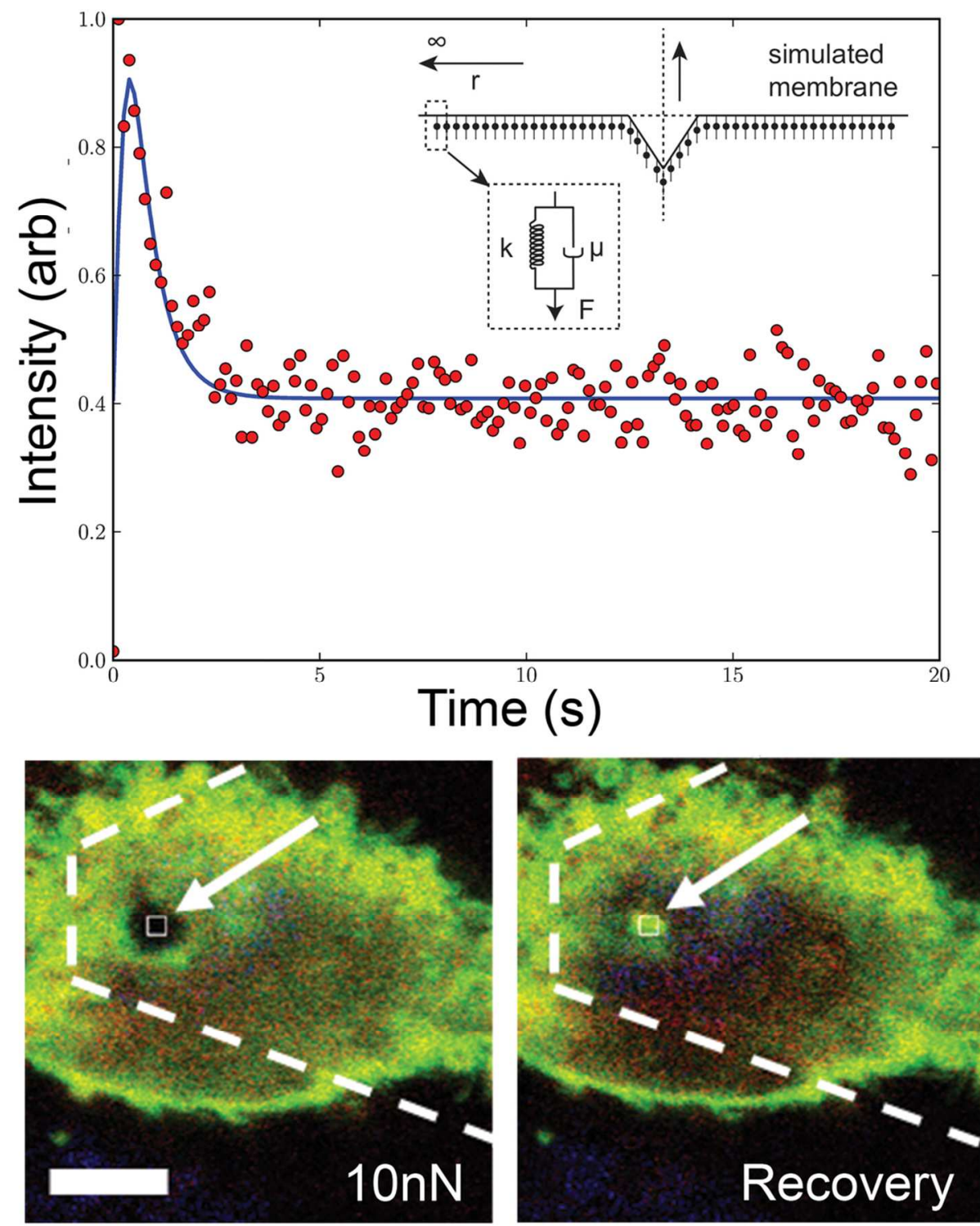

$97 \times 121 \mathrm{~mm}(300 \times 300$ DPI $)$ 


\section{Supplementary Information}

\section{Rapid dynamics of cell shape recovery in response to local deformations}

Kristina Haase ${ }^{1}$, Tyler N. Shendruk ${ }^{2}$, and Andrew E. Pelling ${ }^{1,3,4}$

\section{Supplementary Methods}

\section{Cell culture.}

HeLa cells were cultured at $37^{\circ} \mathrm{C}$ and $5 \% \mathrm{CO}_{2}$ in DMEM with $10 \%$ heat inactivated fetal bovine serum and $1 \%$ penicillin $(100 \mathrm{IU} / \mathrm{mL})$, streptomycin $(1001 \mathrm{~g} / \mathrm{mL}$ ) (Hyclone). Cells were cultured on $100 \mathrm{~mm}$ dishes (Corning) and seeded onto $35 \mathrm{~mm}$ glass bottom dishes (laser-cut $35 \mathrm{~mm}$ plastic culture dishes (TPP) affixed with 1.5 glass $25 \mathrm{~mm}$ round coverslips (Harvard apparatus Canada) using PDMS (Dow Corning)), in $2.5 \mathrm{ml}$ of culture media.

\section{Plasmids and transfections.}

HeLa cells were cultured on $35 \mathrm{~mm}$ glass bottom dishes to $\sim 60 \%$ confluency before transfections. Plasmids $(\sim 0.6 \mu \mathrm{g})$ for the PH domain of PLC- $\delta$ conjugated to EGFP (kind gift of Guillaume Charras) and LifeAct-Ruby (kind gift of Buzz Baum) were diluted in OptiMEM (Invitrogen) as described previously ${ }^{1}$. The transfection complex was completely removed and replaced with culture medium 45 min later. Experiments were performed the following day. Immediately prior to the experiment, Hoechst 33342 (Invitrogen) was used to stain DNA, according to manufacturer specifications.

\section{Drug treatments.}

Cells were pre-treated in a cell culture incubator at $37^{\circ} \mathrm{C}$ and $5 \% \mathrm{CO}_{2}$ immediately before experiments. Cells were pre-treated for 30 min with either the rho-kinase inhibitor Y-27632 (10 $\mu \mathrm{M}$ in DMSO, Sigma) or the microtubule depolymerizer Nocodazole (Noco) (10 $\mathrm{MM}$ in DMSO, Sigma), or pre-treated for 15 min with the actin destabilizing drug Cytochalasin-D (CytD) (10 $\mu \mathrm{M}$ in DMSO, Sigma). In some cases, cells were pre-treated with Y-27632 for 15 min followed by subsequent treatment with Noco for 15 min.

In order to deplete cholesterol levels, methyl- $\beta$-cyclodextrin (M $\beta C D)$, a cyclic oligosaccharide, was used (10 mM diluted in $\mathrm{dH}_{2} \mathrm{O}$, Sigma). Cells were incubated with $\mathrm{M} \beta \mathrm{CD}$ for $30 \mathrm{~min}$ at $37^{\circ} \mathrm{C}$ and $5 \% \mathrm{CO} 2$ in serum-free media followed by washing twice with PBS and complete media change. Considering that $M \beta C D$ was dissolved in a large volume of $\mathrm{dH}_{2} \mathrm{O}$, we used a control population where cells from the same passage were incubated with serum-free medium and the equivalent ratio of $\mathrm{dH}_{2} \mathrm{O}(\sim 500 \mu \mathrm{L} \mathrm{M} \beta \mathrm{CD}$ solution added to $2 \mathrm{~mL}$ media) for $30 \mathrm{~min}$.

\section{Immunochemistry.}

Cells were fixed using 3.5\% paraformaldehyde and permeabilized using $0.5 \% \mathrm{v} / \mathrm{v}$ Triton $\mathrm{X}-100$ at $37^{\circ} \mathrm{C}$. Cells were then stained for actin using Alexa Fluor 546 Phalloidin (Invitrogen), and DNA using DAPI 
(Invitrogen). Microtubules were stained with a mouse monoclonal anti- $\alpha$-tubulin (Abcam) primary antibody followed by an Alexa Fluor 488 rabbit anti-mouse immunoglobin (Invitrogen) secondary antibody. Full details have been described previously ${ }^{2}$.

\section{Image acquisition.}

All images, for live and fixed cells, were acquired with a Nikon TiE A1-R high-speed resonant laser scanning confocal microscope (LSCM), using a 60x (NA $=1.2$ ) water immersion objective lens. Appropriate laser lines and filter sets were employed; GFP was excited using a $488 \mathrm{~nm}$ laser and measured at $525 \mathrm{~nm}$, and RFP was excited using a $561 \mathrm{~nm}$ laser with fluorescence measured at $595 \mathrm{~nm}$. Fixed samples were imaged using LSCM volumes in galvano scanning mode. Imaging of live cell experiments were performed in resonant scanning mode. In this mode, LSCM volume images were captured prior-to and during deformation experiments, and consisted of 30 confocal planes, each 0.5 $\mu \mathrm{m}$ thick. Time-lapse images were performed in a single XY-plane in order to capture the intensity decrease/increase due to deformation/recovery of the cell, at a scan rate $7.69 \mathrm{fps}$. To reduce noise, line averaging $(2 \mathrm{x})$ was used.

\section{Confocal resolution.}

To determine the confocal resolution of GFPs and RFPs used herein, we employed green and red fluorescent $(200 \mathrm{~nm})$ carboxylate-modified microspheres (Invitrogen) diluted in $\mathrm{dH}_{2} \mathrm{O}$ to a final concentration of $10^{6}$, as outlined previously ${ }^{3}$. A $20 \mu$ drop of the diluted stock solution was pipetted onto a clean 1.5 glass coverslip and allowed to dry overnight. LSCM imaging of microspheres was performed the following day with the same excitation wavelength $\left(\lambda_{\text {exc }}=488 \mathrm{~nm}\right.$ for a $525 \mathrm{~nm}$ emission, and $\lambda_{\text {exc }}=561 \mathrm{~nm}$ for $595 \mathrm{~nm}$ emission) and sampling rate $(0.069 \times 0.069 \times 0.18 \mu \mathrm{m})$ used during experiments. Here, we based our theoretical confocal resolution on the Rayleigh criterion ${ }^{3,4}$ :

$$
\begin{aligned}
& \text { Lateral resolution }=\frac{0.51 \lambda_{\text {exc }}}{N A} \\
& \text { Axial resolution }=\frac{0.88 \lambda_{\text {exc }}}{\left(n-\sqrt{n^{2}-N A^{2}}\right)}
\end{aligned}
$$

Based on equations $(1,2)$, (using $n=1.33$ for water) the theoretical resolution for GFP was calculated to be $207 \mathrm{~nm}$ in $\mathrm{x}$ and $\mathrm{y}$, and $567 \mathrm{~nm}$ in z. Theoretical resolution for RFP was calculated as $238 \mathrm{~nm}$ in $\mathrm{x}$ and $y$, and $652 \mathrm{~nm}$ in z. Using an ImageJ plugin, MetroloJ (the plugin and manual can be found: //imagejdocu.tudor.lu/doku.php?id=plugin:analysis:metroloj), we were able to generate a report of the miscrosphere PSF data. Fits of microsphere intensity to a Gaussian equation were used to determine the FWHM. This produced a mean resolution of: 0.248 in $x \mu \mathrm{m}, 0.281 \mu \mathrm{m}$ in $\mathrm{y}$, and $0.701 \mu \mathrm{m}$ in z for GFP microscpheres $(n=10)$. Mean confocal resolution was lower for RFP microspheres $(n=10): 0.305 \mu m$ in $x$, $0.351 \mu \mathrm{m}$ in $\mathrm{y}$, and $1.043 \mu \mathrm{m}$ in $\mathrm{z}$.

\section{Atomic force microscopy.}

A NanoWizard II (JPK Instruments) AFM was mounted on the LSCM to perform integrated AFM-LSCM experiments. All experiments were performed at $37^{\circ} \mathrm{C}$, using a temperature-controlled AFM stage (JPK).The thermal fluctuation method of Hutter and Bechhoefer was used to calibrate AFM tips ${ }^{5}$. The 
sensitivity and stiffness was measured prior to experiments. All AFM cantilevers had an experimentally determined stiffness, $\mathrm{k}=0.08 \pm 0.01 \mathrm{~N} / \mathrm{m}$ (PNP-TR triangular, Nanoworld). Young's modulus (E) was determined by recording force-curves measured over the center of cell nuclei. A shallow region (200 $\mathrm{nm}$ ) of indentation was fit to the Hertz model for a conical tip ${ }^{6}$ to measure local E of the cell (PUNIAS Software) ${ }^{7}$.

Stiffness measurements for $M \beta C D$-treated cells were performed on two controls: cells treated with $M \beta C D$ in serum-free media, as well as cells treated with the addition of the same concentration of $\mathrm{dH}_{2} \mathrm{O}$ to normal DMEM (see Fig. S6b).

\section{Deformation and recovery experiments.}

First, LSCM volume images were recorded prior to and following deformation experiments to ensure cells recovered their initial shape (Fig. S2). Next, tracking of membrane-cortex deformation and recovery involved capturing images in a single XY-plane set approximately $2 \mu \mathrm{m}$ below the apical region of the membrane (as determined by LSCM volume images) (Fig. 1, main text). To capture the initial deformation, images were recorded prior to ( $\sim \mathrm{s}$ ) and during $20 \mathrm{~s}$ of constant force application. The AFM cantilever was set to approach the sample rapidly $(10 \mu \mathrm{m} / \mathrm{s})$, with forces of either 10 or $20 \mathrm{nN}$ applied above the approximate center of cell nuclei (visualized by Hoechst).

A similar method was used to examine the dynamics of cell shape recovery. A series of constant force $(10 \mathrm{nN})$ experiments were performed for varied durations: $15 \mathrm{~s}, 1 \mathrm{~min}$, or $10 \mathrm{~min}$. Again, time-lapse imaging was performed in a single XY-plane during the retraction phase of the tip (following the specified load duration). For long durations (1 and $10 \mathrm{~min}$ ), LSCM volume images were acquired once every minute. For instance, a $10 \mathrm{nN}$ force was applied at the approximate center of the cell for $10 \mathrm{~min}$, during which $11 \mathrm{LSCM}$ volume images were taken corresponding to $\mathrm{t}=0$ (before indentation), $\mathrm{t}=1$ (indentation after $1 \mathrm{~min}$ ) and so on, up to $\mathrm{t}=10$ minutes of applied force. Following force application, the focal plane is manually set to $\sim 2 \mu \mathrm{m}$ below the apical membrane. As the AFM tip is retracted, continuous $\mathrm{XY}$-plane time-lapse images are acquired to capture the recovery of the membrane/cortex ( 30 s). Following this, a final LSCM volume image was captured $(\mathrm{t} \approx 12 \mathrm{~min})$.

\section{Statistics.}

Statistics were calculated using two sample t-tests. Where indicated, one-way ANOVA analyses with post-tests including Levene's test for equal variance, and a means comparison test using the Bonferroni and Tukey methods were employed. Unless otherwise noted, all significance indicates $P<0.050$.

\section{Image analysis of deformation/recovery profiles.}

ImageJ (open-source image processing software, http://rsbweb.nih.gov/ij/) was used for all analysis. A square region of interest (ROI) $\left(0.69 \mu \mathrm{m}^{2}\right)$ was chosen; one containing the deformed cell membrane and cortex. Brightness and contrast settings were adjusted in order to optimize images of live and fixed cells. No other image manipulations were performed. In order to examine the deformation dynamics of the membrane and cortex, time-lapse images were analyzed by capturing mean intensity over time within the ROI (Fig. 1c, main text). Deformation experiments (Fig. 1b) were normalized by averaging initial intensity values observed within the ROI 2 seconds prior to unloading. A value of $I=1$ represents the 
maximum intensity immediately prior to deformation $(\mathrm{t}=0)$, and $\mathrm{l}=0$ the average minimum intensity after the AFM tip is extended. For recovery experiments, $\mathrm{l}=0$ occurs during the deformation while the AFM tip is approached. Following tip retraction, the intensity within the ROI increases as the membrane/cortex pass the imaging plane (maximum normalized to $\mathrm{I}=1$ ).

\section{Non-linear regression of intensity during deformation.}

We chose to fit the deformation intensity profiles to a first-order decay, based on Akaike's (AIC) and Bayesian (BIC) information criteria (Origin v.9.1) ${ }^{8}$. Non-linear regression of intensity-time profiles allowed us to compare decay rates $(\tau(s))$ of the membrane and cortex using equation [S3].

$$
I(t)=I_{o}+A e^{-t / \tau}
$$

Using normalized intensity data, the offset, $\mathrm{I}_{0}$, was set to zero, and the amplitude, $A$, was set to 1 . The only free fit parameter was $\tau$, a characteristic decay rate.

\section{Measuring cellular strain.}

Approximate axial strain measurements were made on cells during long ( 1 and $10 \mathrm{~min}$ ) deformation experiments, as we previously reported ${ }^{1}$. Axial strain was measured in the plane of loading, as:

$$
\varepsilon=d / h_{o}
$$

where $d$ is the deformation and $h_{o}$ is initial cell height. An average of the two measurements were made from orthogonal projections of LSCM volume images.

\section{Derivation of viscoelastic model of relaxation/recovery.}

Here, we propose a simple model for the dynamics and recovery of the membrane/cortex based on the telegraph equation. First, consider a series of masses $(\mathrm{m})$ connected by Hookian springs (with spring constants K) separated by a horizontal distance $\ell$ (Fig. 4a, main text). In the deformed state at a time $\mathrm{t}$ after the tip is removed, these masses are displaced from equilibrium and the $i^{\text {th }}$ mass is displaced by a height $u_{i}^{t}$. This mass is acted upon by the spring force of its neighbours and so is accelerated. Equating the total inertial force to the Hookian spring forces and taking the continuum limit produces the wave equation for an elastic membrane.

Any additional forces that couple the membrane and cortex to the subcellular environment can now be superimposed onto each element causing the simple wave equation to generalize into a form of the telegrapher equation. Here, we employed forces from a single elastic (E) and damping $(\gamma)$ element in parallel acting on each element. Since the elastic and viscous contributions act in parallel, this amounts to a Kelvin-Voigt viscoelastic model and the net force on each element of the surface is then the sum of an elastic and a viscous dissipation term. The resulting telegrapher equation is

$$
m \frac{\partial^{2} u_{i}^{t}}{\partial t^{2}}=k\left[u_{i+1}^{t}-2 u_{i}^{t}+u_{i-1}^{t}\right]-E u_{i}^{t}-\gamma \frac{\partial u_{i}^{t}}{\partial t}
$$

By once again taking the continuum limit of $\ell \rightarrow 0$ as $N \rightarrow \infty$ such that $L=N \ell=L$ is finite and definite the speed of wave propagation $c=\sqrt{K \ell^{2} / m}$, we find 


$$
0=\frac{\partial^{2} u(\vec{r}, t)}{\partial t^{2}}-c^{2} \nabla^{2} u(\vec{r}, t)+\frac{E}{m} u(\vec{r}, t)+\frac{\gamma}{m} \frac{\partial u(\vec{r}, t)}{\partial t}
$$

In this form, the above equation can be described as a surface connected to equilibrium by elements of the Kelvin-Voigt model. Comparing to equation [2] in the main text, we see that $k=E / m c^{2}$ and $\mu=\gamma / m c^{2}$. In the final form of equation [S5], we neglect the inertial term by assuming that we are in the over-damped regime and will not observe inertial dynamics on the membrane surface. We expect a monotonic return to equilibrium, which is reasonable considering that the cell is surrounded by viscous fluid and is largely composed of cytoplasm.

\section{Numerical implementation of the viscoelastic model calculation.}

Equation [S5] does not have an analytic solution and so is solved numerically. The AFM tip is modelled as a cylindrically symmetric cone defined by a solid angle $\Omega=35^{\circ}$ and a maximum indentation depth $h$. An implicit Euler method was found to be stable and employed to determine the displacement $u_{i}^{t}$ at all radial points and times. Non-dimensionalized variables were used in this process. The characteristic length scale was identified to be the maximum displacement $h$, the characteristic time is $\mu h^{2}$. In the following, all variables are non-dimensionalized by these scales. The assumed cylindrical symmetry and over-damped dynamics causes equation [S5] to reduce to

$$
0=\frac{1}{r} \frac{\partial}{\partial r}\left[r \frac{\partial u(r, t)}{\partial r}\right]-\mu \frac{\partial u(r, t)}{\partial t}-k u(r, t)
$$

Applying the implicit Euler method for the spatial derivatives and evaluating them at the future time $t+1$, discretizes equation [S6] into the form

$$
u_{i}^{t}=\left[\frac{a}{r_{i}}-b\right] u_{i-1}^{t+1}+[1+d+2 b] u_{i}^{t+1}-\left[\frac{a}{r_{i}}+b\right] u_{i+1}^{t+1}
$$

where $a=\Delta t /(2 \Delta r), \mathrm{b}=\Delta t /(\Delta r)^{2}$ and $d=k \Delta t$. Equation [S7] holds for all discretization nodes except at the boundaries. The assumed cylindrical symmetry demands a von Neumann boundary condition at the centre i.e. $u_{i-1}^{t+1}=u_{i}^{t+1}$ at $i=0$. We assume a Dirichlet boundary condition of $u_{i}^{t+1}=u_{i}^{t}$ at the last node $i=N$. All of this can be written concisely in the form $\vec{u}^{t}=\boldsymbol{A} \vec{u}^{t+1}$, where $\vec{u}$ is the list of displacements at each node and $\boldsymbol{A}$ is the invertable tridiagonal matrix defined by inspection of Equation [S7]. Because $\boldsymbol{A}$ can be numerically inverted using standard algorithms, the Euler method can calculate all the future displacements from the current displacements via $\vec{u}^{t+1}=A^{-1} \vec{u}^{t}$.

Measurements of intensity profiles do not directly measure displacement height; rather they infer changes in height from the measured intensity at the focal plane, which lies at a depth $f \approx 2 \mu \mathrm{m}$ below the equilibrium surface $u=0$ in the ROI. To estimate the intensity, we assume that fluorescence occurs homogeneously and constantly on the apical membrane. Since the emitted photons must transverse the dispersive intracellular medium to arrive at the focal plane, we approximated the intensity at each point by a Gaussian dispersion about the focal plane. In this way, the total intensity is the integral of the intensity at each point on the focal plane in the ROI. Furthermore, we estimate the intensity at each point to be the integral of the Gaussian dispersion with a variance $\sigma^{2}$ from each point on the membrane 
as given by the displacement equation [S7]. This is done numerically, with cylindrical symmetry and with a numerical cut-off of $r_{c u t}=100 \mathrm{~h}$, used in integrating the intensity at each point in the ROI. In this way, the experimental intensity as a function of time was predicted.

Experimental parameters, such as the maximum tip depth $h$, the focal plane $f$, and the dispersion $\sigma^{2}$ (an optical property that may vary substantially between fluorescent protein expression levels), all vary between experiments. Therefore, these parameters must be prescribed using best estimates, or as fitting parameters along with the viscoelastic properties of interest, $k$ and $\mu$. In our fitting procedure, the average value $h=5 \mu \mathrm{m}$ ( maximum deformation range (see Table S3)), $\sigma=0.2 \mu \mathrm{m}$ (approximate theoretical $x-y$ resolution of GFP) and an ROI radius of $0.469 \mu \mathrm{m}$ are set for all fits. The number of radial nodes is set to $N=500$, the radial step size is $\Delta r=0.06 \mu \mathrm{m}$ and the time step used is $\Delta t=100 \mu \mathrm{s}$. The position of the focal plane $f$, the elastic constant $k$ and viscous coefficient $\mu$ are fit using an iterative least-squares method. This routine is then repeated until the step sizes for $f, k$ and $\mu$ are all less than the prescribed tolerance of $\varepsilon=10^{-5}$. 


\section{Supplementary Tables}

Table S1 I Load magnitude and duration do not affect recovery. Mean recovery constants are displayed following short and long (durations and different load magnitudes. One-way ANOVA analysis with both Tukey and Bonferroni post-tests demonstrated no significant change. Variance was significantly different between populations (Levene's test, $P<0.05$ ). Values shown are means \pm SD.

\begin{tabular}{|l|l|c|c|c|c|c|}
\cline { 3 - 7 } \multicolumn{2}{c|}{} & \multicolumn{2}{c|}{ Membrane } & \multicolumn{2}{c|}{ Cortex } \\
\hline \multirow{3}{*}{$10 \mathrm{nN}$} & Duration & $\mathrm{N}$ & $\mathrm{K}_{1}\left(\mathrm{~s}^{-1}\right)$ & $\mathrm{K}_{2}\left(\mathrm{~s}^{-1}\right)$ & $\mathrm{K}_{1}\left(\mathrm{~s}^{-1}\right)$ & $\mathrm{K}_{2}\left(\mathrm{~s}^{-1}\right)$ \\
\hline \multirow{3}{*}{$20 \mathrm{nN}$} & $15 \mathrm{~s}$ & 8 & $2.66 \pm 1.04$ & $0.08 \pm 0.06$ & $2.84 \pm 0.60$ & $0.05 \pm 0.01$ \\
\cline { 2 - 7 } & $1 \mathrm{~min}$ & 14 & $2.35 \pm 1.04$ & $0.07 \pm 0.06$ & $2.41 \pm 1.00$ & $0.07 \pm 0.04$ \\
\cline { 2 - 7 } & $10 \mathrm{~min}$ & 11 & $2.52 \pm 1.22$ & $0.08 \pm 0.12$ & $2.21 \pm 1.13$ & $0.05 \pm 0.04$ \\
\hline \multirow{3}{*}{20.05} & $15 \mathrm{~s}$ & 6 & $2.41 \pm 0.94$ & $0.05 \pm 0.05$ & $1.53 \pm 0.73$ & $0.03 \pm 0.01$ \\
\cline { 2 - 7 } & $1 \mathrm{~min}$ & 13 & $2.91 \pm 0.54$ & $0.28 \pm 0.43$ & $2.83 \pm 0.64$ & $0.09 \pm 0.05$ \\
\cline { 2 - 7 } & $10 \mathrm{~min}$ & 11 & $3.04 \pm 0.96$ & $0.15 \pm 0.17$ & $2.36 \pm 1.09$ & $0.07 \pm 0.07$ \\
\hline
\end{tabular}

Table S2 | Cytoskeletal and osmotic effects on shape recovery. Characteristic recovery constants of the membrane and cortex are shown following a $1 \mathrm{~min} 10 \mathrm{nN}$ load. "Top" refers to measurements made at the most apical region of the cell (Fig. S3). Values shown are means \pm SD. * indicates $\mathrm{P}<0.05$, and $* *$ indicates $\mathrm{P}<0.08$.

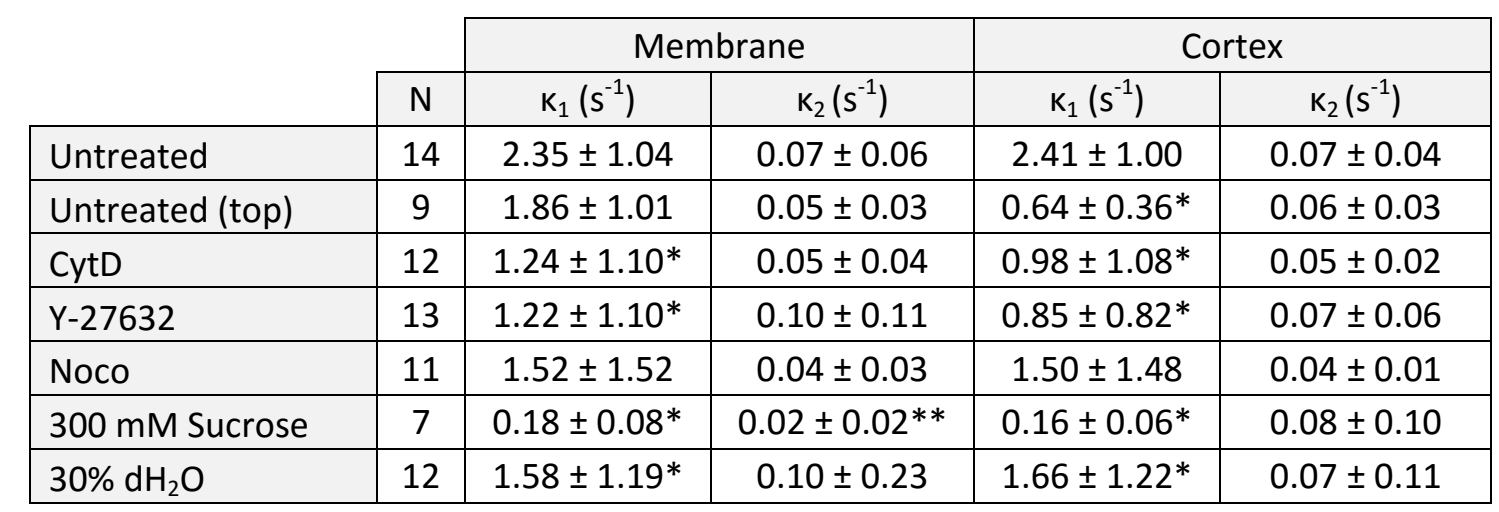

Table S3 | Cytoskeletal and osmotic effects on deformation. Direct measurements of initial height $\left(h_{\circ}\right)$, deformation (d), and approximate axial strain ( $\left.d / h_{o}\right)$ are shown for cells following $1 \mathrm{~min}$ of $10 \mathrm{nN}$ force (unless otherwise noted). Values shown are means \pm SD. ${ }^{*}$ Indicates significance $(P<0.05)$.

\begin{tabular}{|l|c|c|c|c|}
\cline { 2 - 5 } \multicolumn{1}{c|}{} & $\mathrm{N}$ & $\mathrm{h}_{\mathrm{o}}$, height $(\mu \mathrm{m})$ & $\mathrm{d}$, deformation $(\mu \mathrm{m})$ & $\varepsilon$, axial strain $(\%)$ \\
\hline Untreated (10nN) & 20 & $7.62 \pm 1.24$ & $3.73 \pm 1.35$ & $50 \pm 19$ \\
\hline Untreated (20nN) & 20 & $8.07 \pm 2.35$ & $5.04 \pm 1.23^{*}$ & $66 \pm 19^{*}$ \\
\hline CytD & 18 & $9.38 \pm 1.41^{*}$ & $6.45 \pm 1.18^{*}$ & $69 \pm 13^{*}$ \\
\hline Y-27632 & 20 & $9.70 \pm 1.85^{*}$ & $6.36 \pm 1.21^{*}$ & $66 \pm 09^{*}$ \\
\hline Noco & 11 & $7.09 \pm 1.42$ & $4.13 \pm 1.24$ & $58 \pm 12$ \\
\hline $300 \mathrm{mM}^{*}$ Sucrose & 9 & $4.41 \pm 2.26^{*}$ & $1.46 \pm 0.89 *$ & $32 \pm 12^{*}$ \\
\hline $30 \% \mathrm{dH}_{2} \mathrm{O}$ & 17 & $10.08 \pm 1.62^{*}$ & $3.61 \pm 1.26$ & $37 \pm 13^{*}$ \\
\hline
\end{tabular}


Table S4 | Viscoelastic characterization of shape recovery. Shown are mean elastic and viscous components of recovery curves modeled by equation [S3]. * Indicates significant difference with untreated HeLa $(10 \mathrm{nN})(\mathrm{P}<0.05$, using t-test). Values shown are means $\pm \mathrm{SD}$.

\begin{tabular}{|l|c|c|c|c|}
\cline { 2 - 5 } \multicolumn{1}{c|}{} & $\mathrm{N}$ & $\mathrm{k}\left(\mu \mathrm{m}^{-2}\right)$ & $\eta\left(\mathrm{s} \cdot \mu \mathrm{m}^{-2}\right)$ & $\mathrm{K}_{\mathrm{r}}=\mathrm{k} / \eta(\mathrm{s})$ \\
\hline Untreated (10nN) & 8 & $125.01 \pm 64.34$ & $68.08 \pm 84.94$ & $7.17 \pm 6.64$ \\
\hline Untreated (20nN) & 12 & $120.49 \pm 74.55$ & $62.33 \pm 66.09$ & $5.32 \pm 6.56$ \\
\hline CytD & 8 & $58.98 \pm 135.08$ & $141.80 \pm 118.51$ & $* 2.77 \pm 7.60$ \\
\hline Y-27632 & 17 & $3.89 \pm 3.94$ & $71.82 \pm 49.27$ & $* 0.06 \pm 0.03$ \\
\hline Noco & 4 & $203.19 \pm 341.74$ & $703.79 \pm 547.43$ & $8.03 \pm 15.98$ \\
\hline $30 \% \mathrm{dH}_{2} \mathrm{O}$ & 13 & $132.22 \pm 64.34$ & $143.98 \pm 171.71$ & $5.61 \pm 9.48$ \\
\hline
\end{tabular}

Table S5 | Recovery of non-cancerous epithelial cells. Membrane and cortex recovery constants ( $\mathrm{k}$ ) are shown for various epithelial cells. Values shown are means \pm SD. ${ }^{+}$Notes that only $\mathrm{N}=11$ of 20 , and $\mathrm{N}=4$ of 10 datasets were successfully fit for untreated and $M \beta C D$-treated cells, respectively. Fast recovery resulted in discontinuities in intensity curves (thus the mean value is an under-estimate). *Indicates significance with respect to neutrally osmotic $Y-27632+$ Noco-treated cells, $P<0.03$.

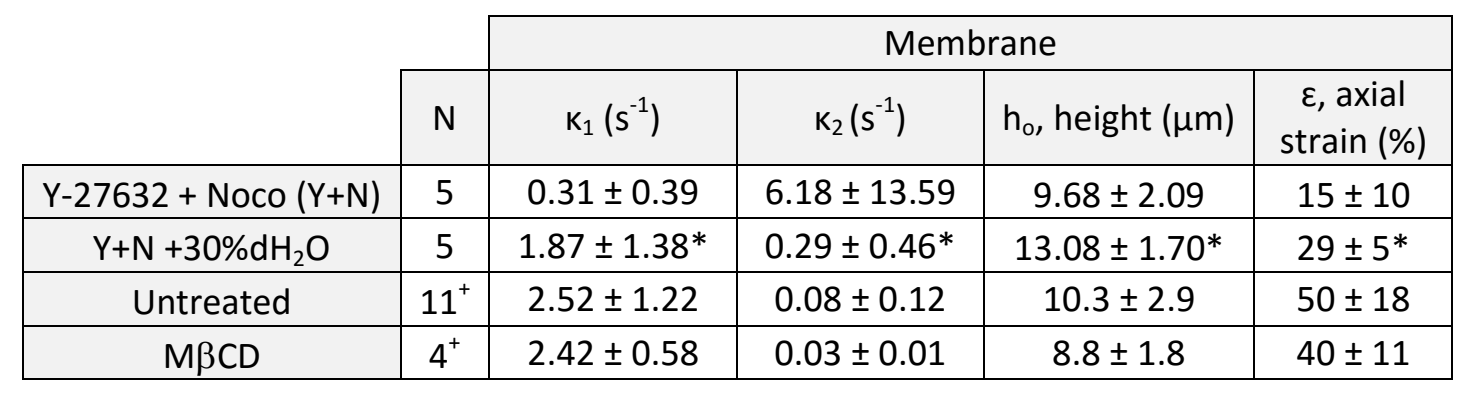

Table S6 | Recovery of non-cancerous epithelial cells. Membrane and cortex recovery constants ( $\mathrm{k}$ ) are shown for various epithelial cells. Values shown are means \pm SD.

\begin{tabular}{|c|c|c|c|c|c|}
\cline { 2 - 6 } \multicolumn{1}{c|}{} & \multicolumn{2}{c|}{ Membrane } & \multicolumn{2}{c|}{ Cortex } \\
\cline { 2 - 6 } \multicolumn{1}{c|}{} & $\mathrm{N}$ & $\mathrm{K}_{1}\left(\mathrm{~s}^{-1}\right)$ & $\mathrm{K}_{2}\left(\mathrm{~s}^{-1}\right)$ & $\mathrm{K}_{1}\left(\mathrm{~s}^{-1}\right)$ & $\mathrm{K}_{2}\left(\mathrm{~s}^{-1}\right)$ \\
\hline MDCK & 21 & $1.73 \pm 1.10$ & $0.11 \pm 0.09$ & $1.11 \pm 0.82$ & $0.13 \pm 0.09$ \\
\hline HEK & 16 & $2.51 \pm 0.94$ & $0.09 \pm 0.06$ & $1.17 \pm 1.08$ & $0.09 \pm 0.03$ \\
\hline CHO & 4 & $3.52 \pm 0.17$ & $0.21 \pm 0.13$ & $1.72 \pm 0.59$ & $0.07 \pm 0.03$ \\
\hline
\end{tabular}




\section{Supplementary Figures}

a

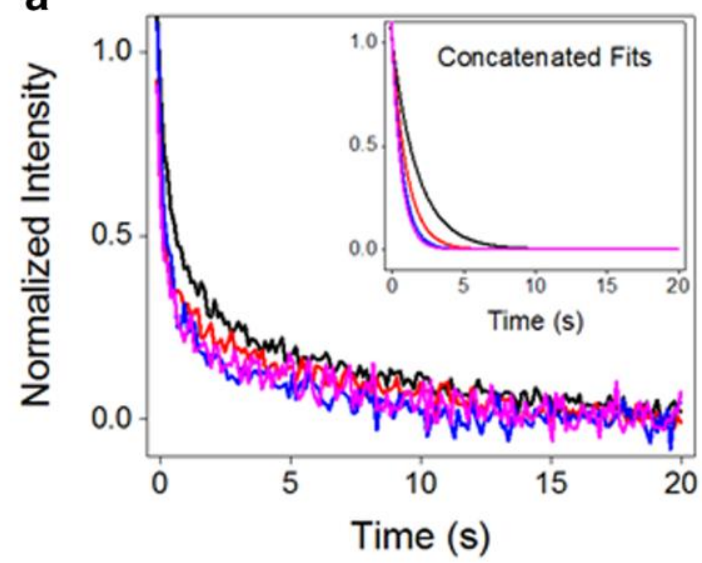

b

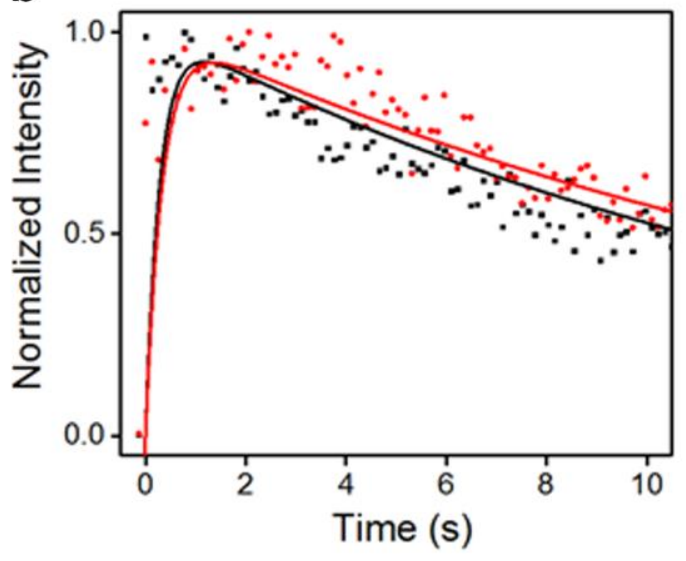

C

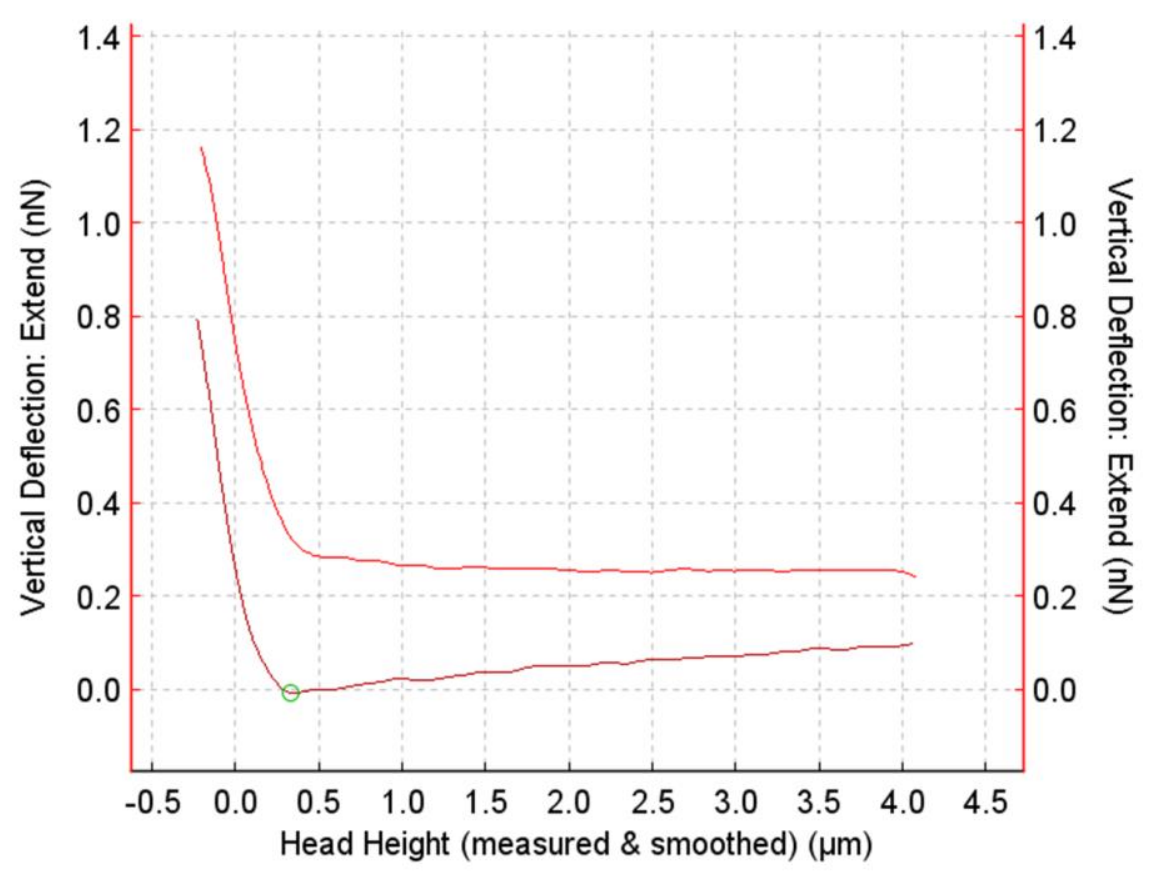

Figure S1 | Membrane and cortex deform and recover simultaneously. a, Normalized plots of intensity over time are shown for the initial $20 \mathrm{~s}$ of membrane $(n=13$, black $-10 n N$, blue $-20 n N)$ and cortex $(n=7$, red $-10 \mathrm{nN}$, magenta $-20 \mathrm{nN})$ deformations following approach of the AFM tip $(t=0)$. Curve variances were significantly different $(P=0.04)$. Inset Concatenated fits to an exponential decay were compared between the membrane $\tau=1.78 \pm 0.04 \mathrm{~s}$ and cortex $\tau=1.04 \pm 0.03 \mathrm{~s}$ (10 nN decay rates) $(\mathrm{P}>$ 0.05 , and $F=0.70)$. Due to the rapid cantilever approach speed $(10 \mu \mathrm{m} / \mathrm{s})$, varying load magnitude (10 to $20 \mathrm{nN}$ ) did not significantly alter the observed response of the membrane or cortex $(P>0.05)$. b. Fits of normalized recovery curves are shown overlaying raw data for an untreated HeLa cell following a $10 \mathrm{nN}$ load applied for $1 \mathrm{~min}$. No significant differences appeared between characteristic times or fits between membrane and cortex or load magnitudes ( $P>0.05$, using paired t-tests and F-test for fits comparison). c, Typical AFM force-curve demonstrating insignificant adhesion between tip and cell (6.9 pN, green 
circle, measured using JPK SPM Data processing software). The majority ( $n=10 / 12$ ) of cells demonstrated adhesion forces orders of magnitude lower than the rate of force retraction during multiple approachretract curves.

a

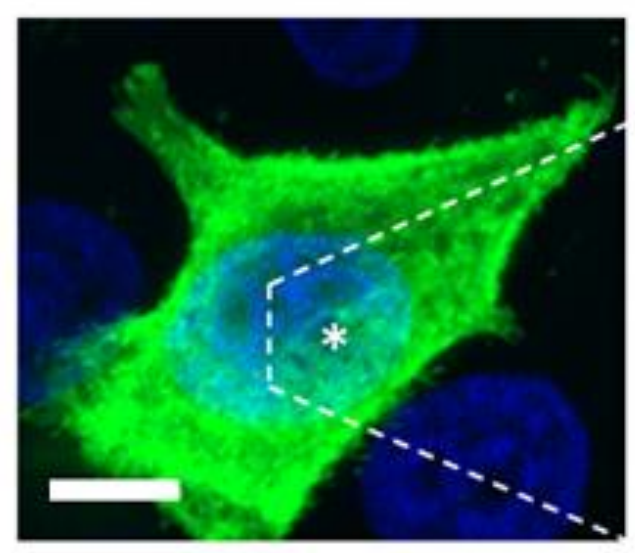

b

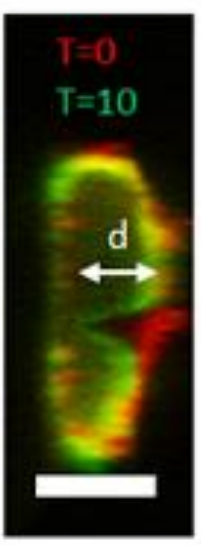

C

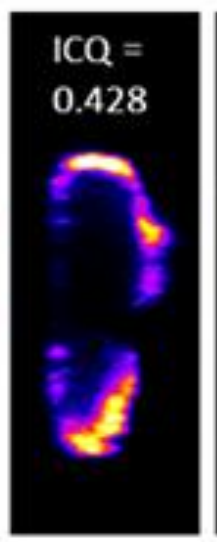

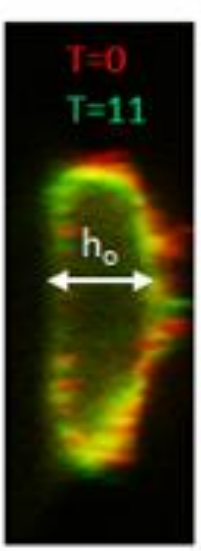

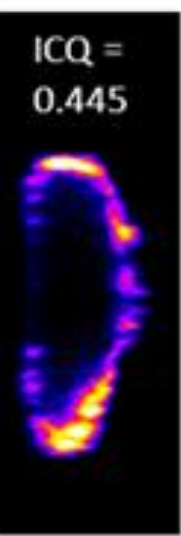

Figure S2 | Cell shape recovery following large deformations. a, Z-projection of a HeLa cell deformed by a $10 \mathrm{nN}$ constant force applied for $10 \mathrm{~min}$. b-c, Shown are red /green overlays of orthogonal projections and corresponding intensity correlation analysis (ICA) and quotients (ICQ). b. Deformation (d) following 10 min of applied force is $c$, recovered, measured in relation to initial height $\left(h_{0}\right)$, following 1 min of force cessation. Positively correlated intensities (bright colours) and increased ICQ values are shown following tip retraction. See reference ${ }^{9}$ for details on ICA. Scale bars are $10 \mu \mathrm{m}$. 


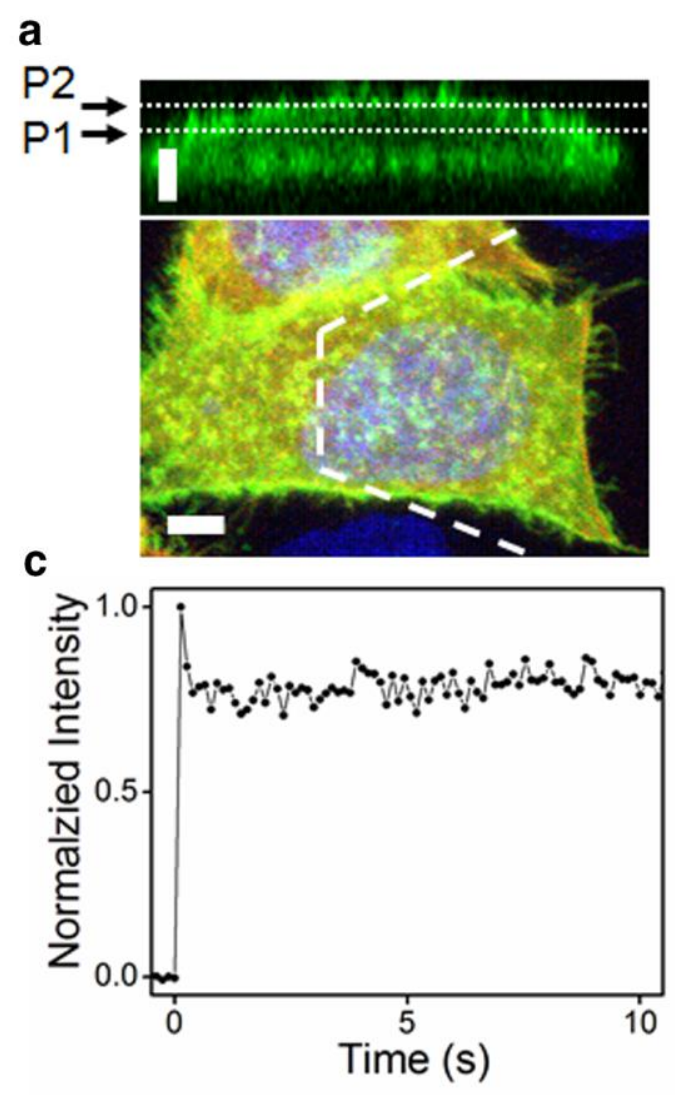

b
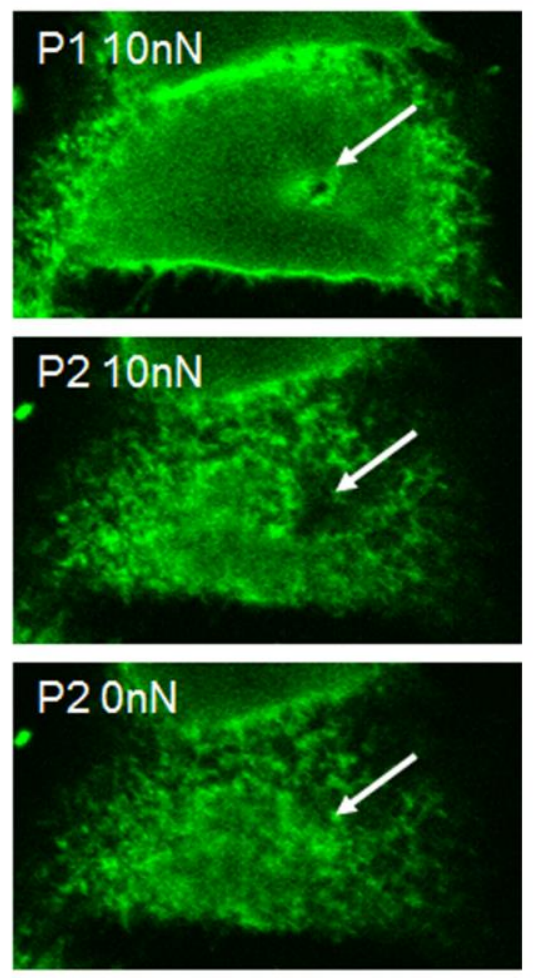

Figure S3 I Imaging plane does not affect recovery. a, LSCM image of a HeLa cell with XZ projection demonstrating the continuous imaging planes $\mathrm{P} 1, \sim 2 \mu \mathrm{m}$ below apical membrane, and $\mathrm{P} 2$, at the apical region. b, XY-images during tip approach demonstrating differences in visible deformations corresponding to P1 and P2 in (a). Arrow indicates deformed region. Scale bars are $5 \mu \mathrm{m}$. c, Intensity profile acquired during continuous imaging in P2 after $10 \mathrm{nN}$ load removal. Sharp intensity peak demonstrates near-instantaneous recovery. 

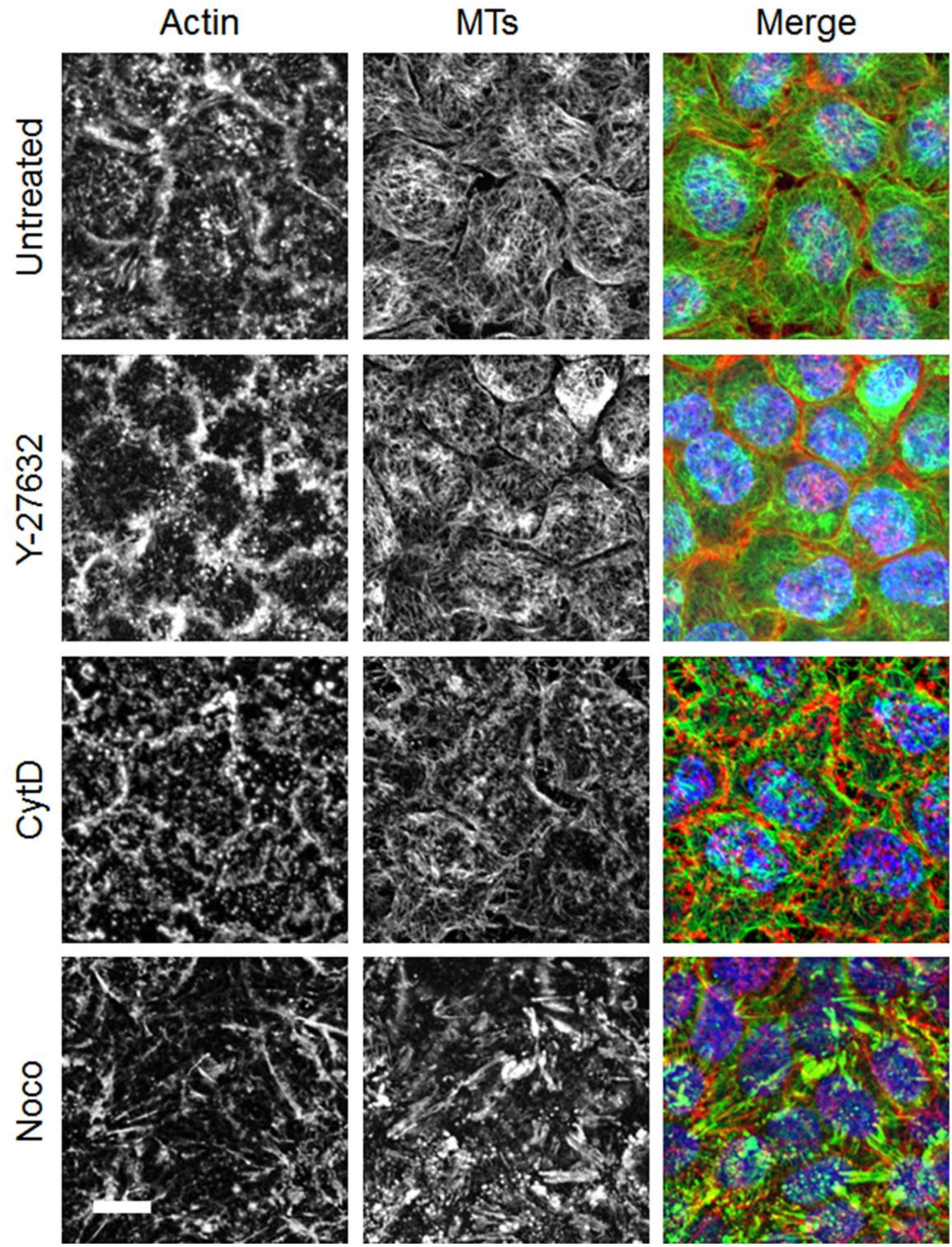

Figure S4 | Cytoskeletal disruption by inhibitors. Immunofluorescent images of fixed cells demonstrate differences in cytoskeletal morphologies following treatment with inhibitors. Scale bar is $10 \mu \mathrm{m}$. 
a

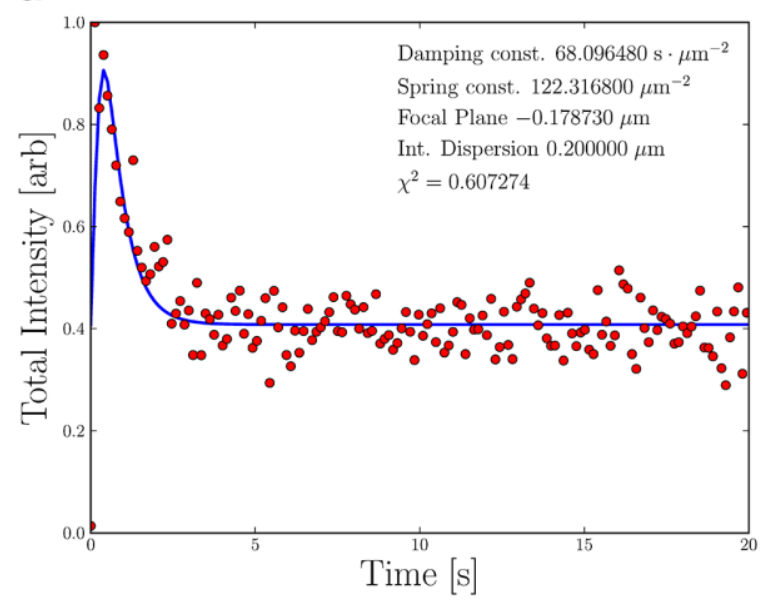

b

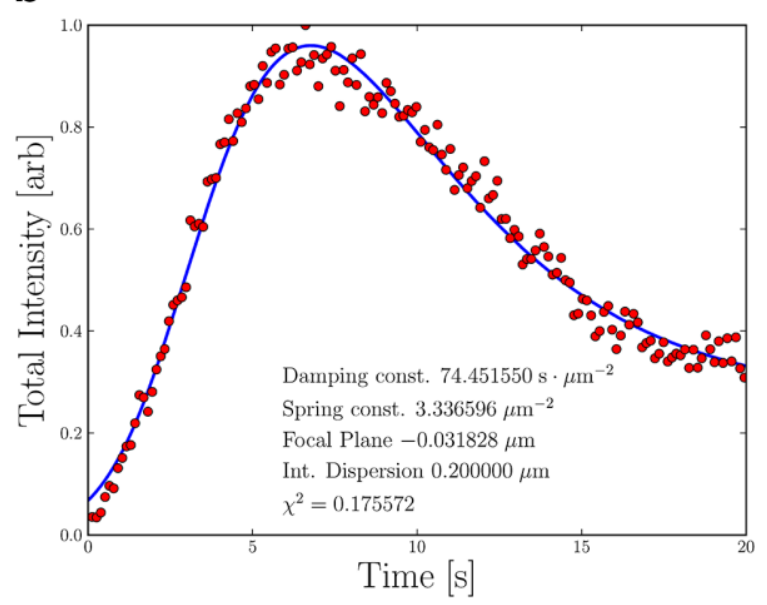

Figure S5 | Simulation of recovery using viscoelastic model. Example outputs from the viscoelastic simulation (equation 2, main text) of a HeLa cell undergoing a, fast recovery, and $\mathbf{b}$, slow recovery following $1 \mathrm{~min}$ of $10 \mathrm{nN}$. Fits, shown in blue, overlay the normalized intensity data (red). 
a
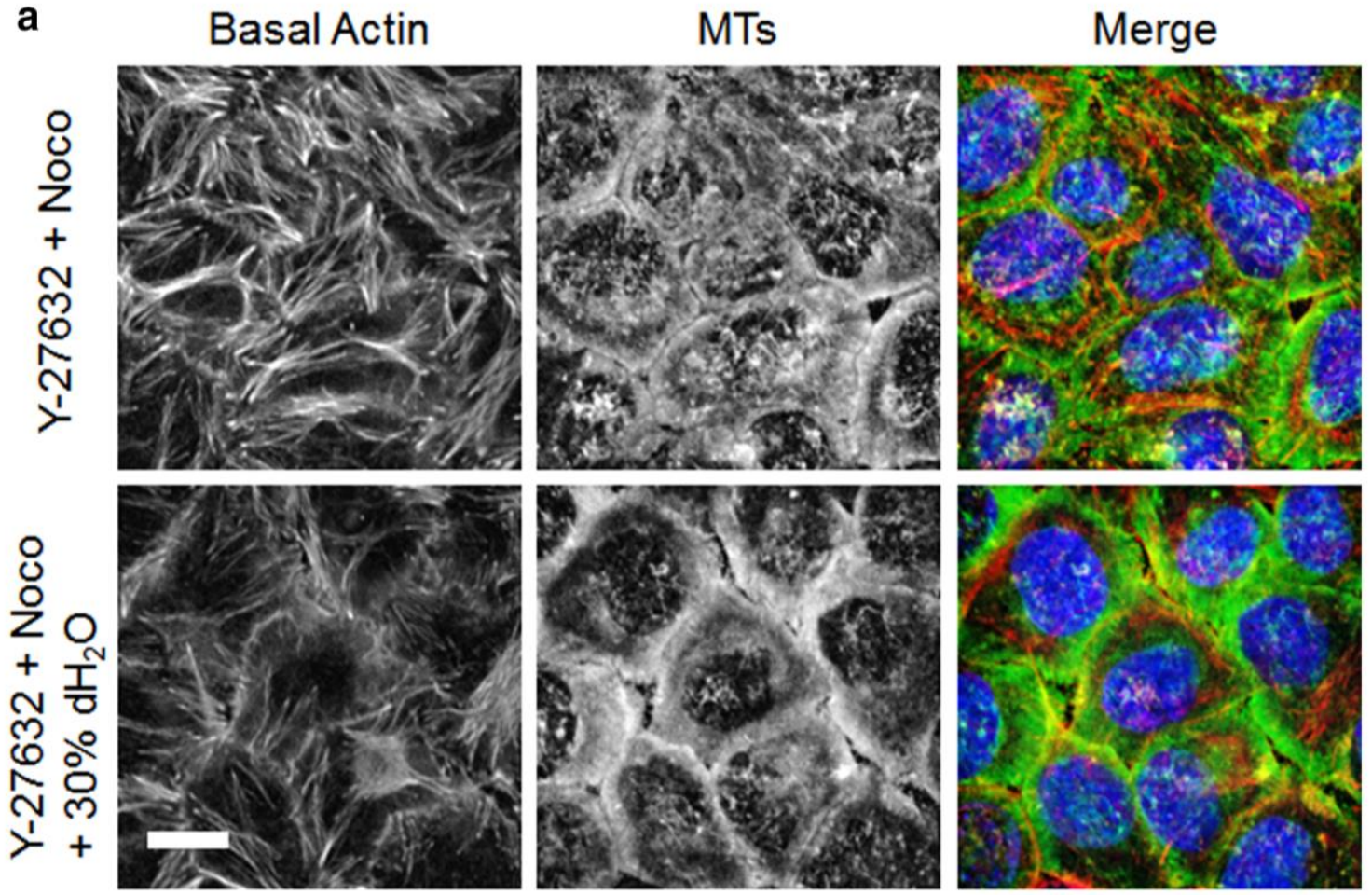

b

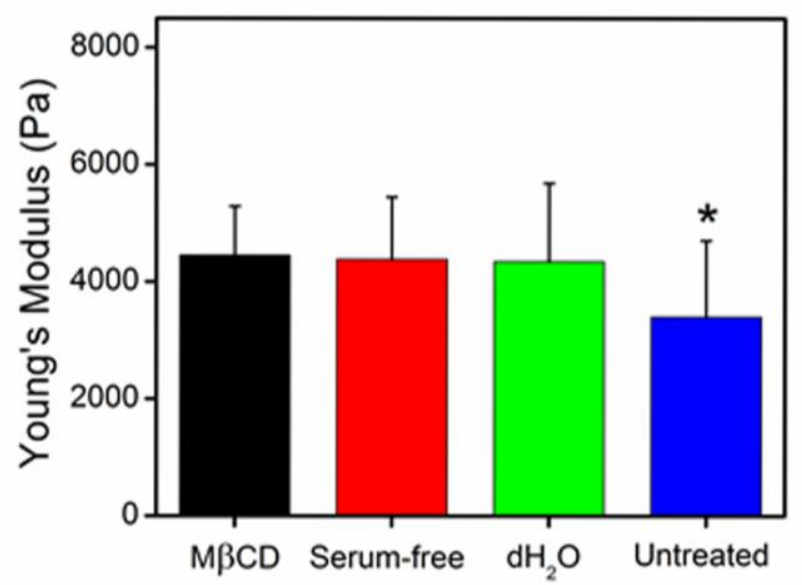

Figure S6 | Osmotic pressure dictates stiffness and recovery. a, Images of fixed cells demonstrate differences in cytoskeletal morphologies following hypo-osmotic shock of Y-27632+ Noco treated HeLa. Scale bar is $10 \mu \mathrm{m}$. b, Young's modulus measurements from AFM force-curves. Shown are mean \pm SD. * Indicates significance in comparison to all other conditions $(P<0.05$, with paired t-tests). 


\section{$\underline{\text { References }}$}

1. Haase K, Pelling AE. Resiliency of the Plasma Membrane and Actin Cortex to Large-Scale Deformation. Cytoskeleton (Hoboken) 2013; 70:494-514.

2. Pelling AE, Veraitch FS, Chu CPK, Mason C, Horton MA. Mechanical Dynamics of Single Cells During Early Apoptosis. Cell Motil Cytoskel 2009; 66:409-22.

3. Cole RW, Jinadasa T, Brown CM. Measuring and interpreting point spread functions to determine confocal microscope resolution and ensure quality control. Nat Protoc 2011; 6:1929-41.

4. Beyer H. Handbuch der Mikroskopie. VEB Verlag Technik, 1985.

5. Hutter JL, Bechhoefer J. Calibration of Atomic-Force Microscope Tips. Rev Sci Instrum 1993; 64:186873.

6. Matzke R, Jacobson K, Radmacher M. Direct, high-resolution measurement of furrow stiffening during division of adherent cells. Nat Cell Biol 2001; 3:607-10.

7. Carl P, Kwok CH, Manderson G, Speicher DW, Discher DE. Forced unfolding modulated by disulfide bonds in the Ig domains of a cell adhesion molecule. P Natl Acad Sci USA 2001; 98:1565-70.

8. Motulsky H. Fitting Models to Biological Data Using Linear and Nonlinear Regression: A Practical Guide to Curve Fitting: A Practical Guide to Curve Fitting. Oxford University Press, 2004.

9. Li Q, Lau A, Morris TJ, Guo L, Fordyce CB, Stanley EF. A syntaxin 1, G alpha(o), and N-type calcium channel complex at a presynaptic nerve terminal: Analysis by quantitative immunocolocalization. J Neurosci 2004; 24:4070-81. 